\title{
An elementary kinetic model for the LSCF and LSCF-CGO electrodes of solid oxide cells: impact of operating conditions and degradation on the electrode response
}

\author{
E. Effori ${ }^{1}$, J. Laurencin ${ }^{1}$, E. Da Rosa Silva ${ }^{1}$, M. Hubert ${ }^{1}$, T. David ${ }^{1}$, M. Petitjean ${ }^{1}$, G. Geneste ${ }^{2}$, \\ L. Dessemond ${ }^{3}$, E. Siebert ${ }^{3}$
}

(1) Univ. Grenoble Alpes, CEA/LITEN, 17 Avenue des Martyrs, 38054 Grenoble/France

(2) CEA, DAM, DIF, F-91297 Arpajon, France

(3) Univ. Grenoble Alpes, Univ. Savoie Mont Blanc, CNRS, Grenoble INP, LEPMI

38000 Grenoble/France

\begin{abstract}
An elementary kinetic model was developed to predict the electrochemical response of porous LSCF and LSCF-CGO electrodes. The model was validated thanks to experiments performed on symmetrical cells using a three-electrode setup. After the model calibration on polarization curves, it has been shown that the model is able to simulate accurately the experimental impedance diagram at OCP and under polarization without additional fitting. Moreover, the evolution of the electrode polarization resistance with the oxygen partial pressure is well reproduced by the model. The electrodes reaction mechanism was thoroughly analyzed and it has been shown that the transition from the bulk path to the surface path depends on the temperature, the polarization and the oxygen partial pressure. The rate-determining steps for the LSCF electrode have been identified at OCP as function of the oxygen partial pressure. Finally, a sensitivity analysis has been performed to study the impact of LSCF demixing on the electrode performances. For a given decomposition, it has been highlighted that the surface passivation would be more impacting than the decrease of the ionic conductivity. Moreover, the impact of the LSCF decomposition would be more detrimental for the electrode performances evaluated in electrolysis mode.
\end{abstract}

Keywords: SOFC, SOEC, modeling, oxygen electrode, LSCF, LSCF-CGO, Electrochemical impedance spectroscopy. 


\section{Introduction}

Solid Oxide Cells (SOCs) are high-temperature electrochemical devices that can be used in either fuel cell (SOFCs for Solid Oxide Fuel Cells) or electrolysis mode (SOECs for Solid Oxide Electrolysis Cells). The high operating temperatures $\left(\approx 750-850^{\circ} \mathrm{C}\right)$ allow reaching very high efficiencies without the use of expensive electro-catalysts [1]. In addition, SOFCs can be fed under a large range of fuels, from hydrogen to hydrocarbons, contrary to the low-operatingtemperature technologies such as Proton-Exchange Membrane (PEM) or Alkaline Fuel Cell (AFC) [2]. In the same way, SOECs are able to co-electrolyze carbon dioxide and steam to produce a syngas composed of carbon monoxide and hydrogen [3]. However, despite all these advantages, the elevated operating temperatures activate materials aging with chemical decomposition, reactivity between the cell components and electrode microstructural evolution $[4,5,6,7]$. These phenomena result in a significant degradation in cell performances upon operation, limiting the SOCs lifetime and delaying the deployment of this technology in the marketplace.

SOC is composed by a dense electrolyte in Yttria Stabilized Zirconia (YSZ) sandwiched between two porous electrodes. The hydrogen electrode is usually made of Nickel and YSZ cermet (Ni-YSZ) while Mixed Ionic and Electronic Conductors (MIECs), such as Lanthanum Strontium Cobalt Ferrite (LSCF) are used as oxygen electrode [8, 9]. Recently, it has been proposed to add Cerium Gadolinium Oxide (CGO) in LSCF to form a LSCF-CGO composite electrode exhibiting high performances even at intermediate operating temperatures $(\approx 650$ $\left.750^{\circ} \mathrm{C}\right)[10,11,12,13]$. It is worth noting that a barrier layer in CGO is usually added between the oxygen electrode and the electrolyte in order to limit the chemical reactivity between LSCF and YSZ [14]. Nevertheless, despite the barrier layer, several authors have shown that secondary phases such as $\mathrm{SrZrO}_{3}$ zirconates can appear during the cell manufacturing due to the high temperature of the electrode sintering $[15,16,17]$.

Nowadays, it is widely recognized that a significant part of the overall cell degradation upon 'normal' operation comes from the oxygen electrode [18, 19]. Among all the underlying mechanisms that affect the oxygen electrode stability (chromium poisoning, delamination, formation of secondary phases, etc.), the LSCF demixing is considered as one of the most detrimental phenomena [20]. It consists in the migration and segregation of the $S r_{L a}^{\prime}$ from the perovskite lattice resulting in the formation of a SrO strontium oxide film at the LSCF surface. As the $\mathrm{SrO}$ is an electrical insulating compound blocking the reactions of oxygen exchange, the process leads to the LSCF surface passivation [21, 22, 23, 24]. For example, Wang et al. [23] have shown that the global exchange kinetic constant $k_{c h e m}$ after ageing at $700^{\circ} \mathrm{C}-800^{\circ} \mathrm{C}$ is 
decreased by an order of magnitude and they attributed this evolution to the LSCF surface passivation. However, Kim et al. [22] have recently suggested that the decrease of $k_{c h e m}$ 'cannot be accounted for only the surface coverage of inactive $\mathrm{Sr}$ segregation' and they proposed that the kinetic constant could also be affected by the stoichiometry change with $\mathrm{Sr}$ deficiency on the 'clean' part of the LSCF surface. Moreover, the oxygen chemical diffusivity (or ionic conductivity) of LSCF is also decreased by the loss of $\mathrm{Sr}$ in the bulk of electrode due to the LSCF decomposition $[22,25]$. All these phenomena are expected to cause the degradation of the electrode performances even if their impact on the electrode response remains nowadays unclear. In this context, the exact role of the operating conditions on the demixing is still under investigation. Nonetheless, it has been shown that the rate of the phase decomposition is strongly accelerated by the anodic current [20]. For instance, Frey et al. [18] have shown that the demixing of the LSCF material is enhanced for a stack operated in SOEC mode compared to stacks operated in SOFC mode. Laurencin et al. [20] have proposed that the depletion of oxygen vacancies within the electrode under anodic current, i.e. in SOEC mode, could activate the LSCF decomposition.

Since the electrochemical behavior depends strongly on the elementary reaction mechanism taking place at the electrode surface, its deep knowledge is of fundamental importance in order to better analyze the degradation. However, in spite of many studies, the LSCF and LSCF-CGO reaction mechanisms are not fully understood yet. Nevertheless, it is generally admitted that the bulk path (related to the oxygen solid-state diffusion in LSCF and the oxygen exchange at the electrode surface) is predominant for the electrode operated under cathodic current $[26,27,28$, 29]. It has been more recently highlighted that a change of reaction mechanism arises at low anodic over-potential, from the bulk to the surface path (defined by the direct charge transfer at the Triple Phase Boundary lines (TPBls)) [30, 31]. Regarding the LSCF-CGO composite, some studies have suggested that the reaction mechanism is entirely controlled by the surface path whatever the electrode polarization $[22,32]$.

To date, many models have been already published for the LSCF electrode $[26,27,30,31,33$, $34,35,36,37,38,39,40]$. Adler and coworkers [26] were the first to propose an analytical model to express the impedance at the Open Circuit Potential (OCP) for the porous MIEC. In their work, they considered an equivalent homogenous electrode taking into account the bulk path with one global step of oxygen exchange between the gas and the MIEC, which was treated as a pure chemical reaction. With the simplification of an infinite electrode thickness, the 
solution is equivalent to a Gerischer-type impedance [41] and is referred as the so-called 'ALS' model [26]. This approach has been used and improved by many authors for analytical or numerical models for the LSCF and LSCF-CGO electrodes [36, 37, 38, 42, 43]. For instance, Mortensen et al. [43] have proposed an analytical solution to compute the impedance diagrams for MIEC-CGO composite electrodes. In our group, numerical stationary and dynamic models have been developed for the porous LSCF and LSCF-CGO electrodes by taking into account the bulk and surface paths $[30,39]$. The whole mechanism was splitted into four steps considering only neutral oxygen adatom species attached on the LSCF surface. Therefore, no interaction between the adsorbed species was assumed and the surface coverage at equilibrium was related to the oxygen partial pressure by the Langmuir isotherm. It has been found that this approach is able to predict accurately the electrode polarization curves as well as the impedance diagrams at $P_{O_{2}}=0.21 \mathrm{~atm}$ under cathodic and anodic dc currents [31, 32]. However, it is well known that charged oxygen species are likely to be found on oxide surfaces [44]. Fleig et al. $[45,46]$ have underlined that the charge of adsorbed oxygen ions on the surface could affect the global electrode kinetic and its dependence with the oxygen partial pressure, due to electrostatic interactions. A model assuming a uniform double layer induced by the negative adsorbed species counterbalanced by the positive holes in LSCF was proposed to take into account those interactions.

From this context, the modeling with a full elementary description could improve the models predictability especially for the oxygen partial pressure dependence of the electrode kinetics. However, it must be emphasized that the experimental validation remains questionable due to the large number of unknown parameters. Indeed, in the particular case of porous electrodes, in contrast to well-defined geometries such as the pattern electrodes, it is essential to know all the microstructural properties characterizing the electrode morphology (volume fractions, tortuosity factors, specific surface areas and density of TPBls). The measurements of these parameters of $3 \mathrm{D}$ electrode reconstructions allow decreasing the number of fitted parameters and hence to enhance the relevance of the validation.

To date, very few full elementary models have been specifically dedicated for porous LSCF and LSCF-CGO electrodes. None of them has been validated with the knowledge of real microstructural parameters. Gong et al. [47] have proposed a stationary model for the MIEC in which the reaction mechanism was divided in five reactions taking into account the presence of oxygen ions on the electrode surface. Even if the model was not validated, they found a transition from the bulk to the surface path arising under cathodic polarization when applied to LSM-type electrode. Ma et al. [40] have recently published a stationary elementary kinetic 
model for porous LSCF coupled with Density Functional Theory (DFT) simulations. The model was validated on one $\mathrm{i}-\mathrm{V}$ curve taken from the literature at $800^{\circ} \mathrm{C}$ under $P_{O_{2}}=1 \mathrm{~atm}$. In contradiction to the statements reported in $[30,31]$, they claimed that the surface path is negligible even in SOEC mode and all the kinetic simulations were carried out only considering the bulk path. Yurkiv et al. [48] have proposed a dynamic elementary kinetic description for the LSCF-CGO composite in which the LSCF and CGO was modeled as an equivalent medium for oxygen solid-state diffusion and by neglecting the surface path. For the validation, the simulated impedance diagrams at OCP under air was confronted with the experimental data measured between $500-800^{\circ} \mathrm{C}$. However, although the three contributions in the impedance diagrams at high, medium and low frequencies were identified, the agreement between the simulated on the experimental spectra was not fully satisfactory. Finally, Donazzi et al. [49] have built a quasi-elementary model taking into account both the surface and bulk paths for the LSCF-CGO composite. The authors have considered a dissociative adsorption step followed by an ionization on the LSCF surface. The model was validated on impedance diagrams at OCP from $560^{\circ} \mathrm{C}$ to $700^{\circ} \mathrm{C}$ and three oxygen partial pressure $\left(P_{O_{2}}=0.05 ; 0.1\right.$ and $\left.0.21 \mathrm{~atm}\right)$. In this case, it has been found that the reaction mechanism would be controlled by the surface path. From this literature review, it appears that there are still a controversy on the dominant reaction pathway for the LSCF and LSCF-CGO electrodes. Indeed, a full validation for the elementary model simultaneously applied to both the LSCF and LSCF-CGO porous electrodes is still missing with the knowledge of the microstructural properties and a set of relevant electrochemical characterizations.

In this work, our previous models for the porous LSCF and LSCF-CGO electrodes have been extended with a full elementary kinetic description for both the surface and bulk paths. The set of partial differential equations has been solved by keeping the full non-linearity of the system to compute the dynamic electrode response even for non-linear perturbations. Because of the large number of unknown parameters inherent to this kind of approach, a special attention has been paid to achieve a thorough and relevant model validation. For this purpose, the microstructural properties of the tested LSCF and LSCF-CGO electrodes have been extracted from 3D reconstructions obtained by Focused Ion Beam - Scanning Electron Microscopy (FIBSEM) tomography. Besides, in order to reduce as far as possible the uncertainties on the parameters estimation, a wide range of experimental conditions have been explored (polarization curves, impedance spectra at OCP and under dc currents at different temperatures 
and oxygen partial pressures). It was checked that the fitted values for the reaction rate constants and diffusivities were similar for both electrodes. Thanks to the detailed surface reaction mechanism of this elementary model, the impact of the phase demixing on the LSCF based electrode response has been investigated through a sensitivity analysis.

\section{Experimental}

\subsection{Materials and studied cells}

Two symmetrical button cells made of $\mathrm{La}_{0.6} \mathrm{Sr}_{0.4} \mathrm{Co}_{0.2} \mathrm{Fe}_{0.8} \mathrm{O}_{3-\delta}$ and $\mathrm{La}_{0.6} \mathrm{Sr}_{0.4} \mathrm{Co}_{0.2} \mathrm{Fe}_{0.8} \mathrm{O}_{3-}$ ${ }_{\delta} / \mathrm{Ce}_{0.8} \mathrm{Gd}_{0.2} \mathrm{O}_{2-\delta}(50 / 50 \mathrm{wt}$. \%), respectively, were prepared by screen-printing the electrodes (thickness $=35 \mu \mathrm{m}$, diameter $=11.2 \mathrm{~mm}$ ) on both sides of a circular 8YSZ electrolyte (thickness $=260 \mu \mathrm{m}$, diameter $=25 \mathrm{~mm})($ Fig. 1a). To avoid any misalignment between the Working Electrode (WE) and the Counter Electrode (CE), a particular attention was paid during the cell manufacturing to position both electrodes at the center of the electrolyte disk. Indeed, even a slight dissymmetry between the two electrodes can lead to major distortions in the impedance diagrams $[50,51]$. Finally, a CGO barrier layer (thickness $=2 \mu \mathrm{m}$ ) was added between the electrodes and the electrolyte to prevent the formation of secondary phases [6].

\subsection{Experimental set-up}

The symmetrical cells were tested using a three-electrode set-up (Fig. 1b). The Reference Electrode (RE) consisted of a platinum wire ring applied on the edge of the electrolyte membrane as far as possible from the WE. In this configuration, the geometrical rules for the reference electrode positioning were fulfilled [52]. Two platinum grids with a mesh of 3600 meshes $\cdot \mathrm{cm}^{-2}$ and a surface equal to the area of the electrodes were used as current collectors. It can be noticed that a $1 \mathrm{~mm}$ thick disk in porous gold was inserted between the ceramic housing and the platinum grid in such a way that each electrode surface can be considered as equipotential. An additional weight of $0.7 \mathrm{~kg}$ was added on the top of the cell chamber, in order to enhance the electrical contact between the grids and the electrodes (Fig. 1b). It is worth noting that the entire set-up was made of alumina to avoid any contamination of the sample in operation. The supplied gas was a synthetic mixture of nitrogen and oxygen, which was introduced in the cell housing using inlet and outlet pipes as shown in Fig. $1 \mathrm{~b}$ (with a total $\mathrm{O}_{2}$ and $\mathrm{N}_{2}$ flow rates of $0.44 \mathrm{Nl} \cdot \mathrm{h}^{-1}$ and $1.66 \mathrm{Nl} \cdot \mathrm{h}^{-1}$, respectively). According to the design of the chamber, it is roughly estimated that around one third of the inlet flux was passing through each 
electrode (i.e. each electrode was fed with an inlet flux of around $F_{O_{2}}^{\text {inlet }} \approx 0.146 \mathrm{Nl} \cdot \mathrm{h}^{-1} \cdot \mathrm{cm}^{-2}$ and $F_{N_{2}}^{\text {inlet }} \approx 0.553 \mathrm{Nl} \cdot \mathrm{h}^{-1} \cdot \mathrm{cm}^{-2}$, respectively). Finally, a thermocouple was positioned close to the cell to monitor constantly its temperature (Fig. 1b).

\subsection{Testing and measurements conditions}

Before starting the measurements, the cells were heated at a rate of $1^{\circ} \mathrm{C} \cdot \mathrm{min}^{-1}$ up to $800{ }^{\circ} \mathrm{C}$. This temperature was maintained for 48 hours to improve the electrical contact between the electrodes and the current collectors. During this period, the cells were monitored periodically by Electrochemical Impedance Spectroscopy (EIS) until the complete stabilization of the diagrams at OCP. Afterwards, the electrochemical measurements were carried out at $750^{\circ} \mathrm{C}$, 700 and $650{ }^{\circ} \mathrm{C}$ under air condition, keeping a high oxygen gas flow rate in order to limit as much as possible the electrode overpotential due to the gas conversion $\left(P_{O_{2}}=0.21 \mathrm{~atm}\right.$ and $F_{O_{2}}^{\text {inlet }}=0.146 \mathrm{Nl} \cdot \mathrm{h}^{-1} \cdot \mathrm{cm}^{-2}$ ). At each operating temperature, polarization curves were recorded in galvanostatic mode with a current step of $1 \mathrm{~mA} \cdot \mathrm{s}^{-1}$ together with impedance diagrams at OCP. At the reference temperature of $700^{\circ} \mathrm{C}$, the experimental dataset was complemented by the acquisition of impedance diagrams under anodic and cathodic dc currents $\left(i_{\mathrm{dc}}= \pm 50\right.$ $\mathrm{mA} \cdot \mathrm{cm}^{-2}$ ) for both studied cells. Besides, the impedance diagrams were recorded at OCP by changing the gas composition in the oxygen partial pressure range from $0.10 \mathrm{~atm}$ to $1 \mathrm{~atm}$.

The EIS diagrams were acquired in a frequency range of $10 \mathrm{kHz}-0.01 \mathrm{~Hz}$ by applying a sinusoidal perturbation on the current with an amplitude of $\left|i_{a c}\right|= \pm 10 \mathrm{~mA} \cdot \mathrm{cm}^{-2}$. Ten points per decade are required at least and an integration time of $1 \mathrm{~s}$ per point was chosen.

All the measurements were conducted using an Autolab potentiostat PGSTAT302N coupled with a frequency response analyzer (FRA2). For the sake of clarity, the series resistances $\left(R_{S}\right.$ corresponding to the resistive contributions of the YSZ pellet plus the contact resistances) were taken at the intercept with the real axis of the impedance data at high frequencies and removed from all the presented impedance diagrams. Moreover, the electrode polarization curve was obtained by removing the ohmic loss from the recorded voltage $E^{\text {meas }}: \eta(V / r e f)=$ $E^{\text {meas }}(V / r e f)-R_{s} i$. 


\subsection{FIB-SEM reconstructions}

The microstructural properties of the studied electrodes were obtained by FIB-SEM tomography reconstruction. The details of this technique and its modus operandi have been already described in [32]. For the LSCF electrode, a volume of $22.84 \times 21.36 \times 22.14 \mu \mathrm{m}^{3}$ with a voxel size of $10 \mathrm{~nm}$ has been specifically acquired for the present study (Fig. 2a). For the LSCF-CGO composite electrode, a reconstructed volume of $19.87 \times 11.5 \times 11.5 \mu \mathrm{m}^{3}$ with a voxel size of $10 \mathrm{~nm}$ was already obtained and presented in [32] (Fig. 2b). For both reconstructions, the raw image has been segmented according to the procedure described in [53] before extracting a cubic subvolume of $10 \times 10 \times 10 \mu \mathrm{m}^{3}$ for the analyses. A set of numerical tools thoroughly detailed in $[54,55]$ were used to compute all the microstructural parameters required for the simulations. They correspond to the interfacial specific surface areas, the mean pores radius, the volume fractions, the tortuosity factors of the phases and the density of TPBls for the composite electrode. For what concerns the LSCF electrode, the density of TPBls and the LSCF/CGO interfacial specific surface area have been measured on a region of interest corresponding to a rectangular volume of $10 \times 4 \times 10 \mu \mathrm{m}^{3}$ taken at the CGO barrier layer.

\section{Model description}

The model considers an equivalent homogeneous medium of an isothermal slice of porous LSCF or LSFC-CGO electrode including the CGO barrier layer (Fig. 3a). The effective properties for the model are computed on the 3D reconstructions and are expressed through the electrode microstructural properties [56]. The model was developed to simulate the electrode response for both stationary and dynamic behaviors. The reaction mechanism, which is composed of the bulk and surface paths for the oxygen transfer, has been divided in a sequence of pure elementary steps. For this purpose, the presence of neutral oxygen atoms, adsorbed ions and molecules have been assumed on the LSCF surface $[57,58]$.

\subsection{Reaction mechanism}

For the sake of clarity, the implemented reaction mechanism is described hereafter only for the LSCF-CGO electrode in anodic polarization. The model for the LSCF electrode can be deduced from the composite one by considering that the reactions occurring at the TPBls and at the 
LSCF/CGO interface do not extend in the whole electrode volume but are restricted at the interface with the electrolyte.

The detailed reaction mechanism is described in Fig. $3 b$ in which the blue and red arrows are related to the bulk and surface paths, respectively. All the reactions implemented in the model are listed in Table I using the "Kröger-Vink" notation along with the expressions of their kinetic rates. The bulk path is composed by the migration of the oxygen ions in CGO, followed by the ionic transfer at the LSCF/CGO interface (R1), the oxygen diffusion in the bulk and a final oxygen excorporation (R2). For this last step, the oxygen ion in LSCF reacts with a hole coming from the electrode to produce an oxygen ion attached on the surface. In parallel, the surface path is defined by the direct electrochemical oxidation at the TPBls (R3). The two parallel pathways merge in a common path depicted by green arrows in Fig. 3b. In this last part of the reaction mechanism, the oxygen ions diffuse on the LSCF surface and are further oxidized to form neutral oxygen ad-atoms (R4). After diffusion, these species can react to produce attached $\mathrm{O}_{2}$ molecules (R5) that can also diffuse before being released into the porosities (R6). Finally, the $\mathrm{O}_{2}$ gaseous molecules can be transferred by gas diffusion in the porosity network up to the gas channel.

Because of this elementary kinetic description, the presence of adsorbed charged species (oxygen ions) is assumed on the LSCF surface. As proposed by Fleig [45], a double layer can arises at the LSCF/gas interface due to the accumulation of oxygen ad-ions whose charges are counterbalanced by holes in LSCF. This local double layer yields a surface electrostatic potential step $\chi$ which is characterized by a capacitance $C_{d l}^{\text {surface }}$ :

$$
\chi(\mathrm{z})=\chi_{L S C F}^{\text {bulk }}-\chi_{L S C F}^{\text {surf }}=\frac{\Gamma F \theta_{O^{-}-s_{L S C F}}(z)}{C_{d l}^{\text {surface }}}
$$

where $\Gamma$ is the density of available sites on the LSCF surface, F is the Faraday's constant and $\theta_{O^{-}-s_{L S C F}}$ the surface coverage of the oxygen ad-ions. It is worth noting that Eq. (7) stands for a low concentration of adsorbed species (i.e. for a diluted solution) when there is no restriction on the number of available sites. This electrostatic potential is supposed to vary with the coverage rates all along the electrode thickness. On the other hand, the electrode potential $E$ is classically expressed as the difference between the local electronic potential in LSCF ( $\left.\varphi_{L S C F}\right)$ and the local ionic potential in $\mathrm{CGO}\left(\varphi_{C G O}\right)$ : 


$$
E(z)=\varphi_{L S C F}(z)-\varphi_{C G O}(z)=+\frac{\tilde{\mu}_{h} \cdot}{F}-\frac{\tilde{\mu}_{V_{o}}}{2 F}
$$

where $\tilde{\mu}_{h} \cdot$ and $\tilde{\mu}_{V} \cdot \bullet$ denote the electrochemical potentials $\left(\mathrm{J} \cdot \mathrm{mol}^{-1}\right)$ for the holes in LSCF and the oxygen vacancies in CGO.

The transport equations for the fluxes and the mass and charge conservations are provided in Table II.

\subsection{Kinetic rates and transport phenomena}

Expression for the kinetic rates - As shown in Tab. I for Eqs. (1-6), all the kinetic rates $v_{(i)}$ have been expressed as the difference between the forward and backward reactions. It can be noticed that the charge transfer at TPBls (R3) is an electrochemical reaction and its kinetic is dependent on the local electrode potential $E(z)$ through the classical Butler-Volmer equation (Eq. (3)). Even if there is no change in the oxidation state between the products and reactants for the ionic transfer $\mathrm{R} 1$, this reaction is still supposed to be affected by the electrode potential at the LSCF/CGO interface. Its kinetic is thus written using a Butler-Volmer formalism as reported in Eq. (1) [30]. The oxidation/reduction steps (R2 and R4) arising at the LSCF surface are two electrochemical reactions and their kinetic rates are also assumed to be affected by the surface potential step $\chi(z)$ (cf. Eqs. (2) and (4)) [46]. Finally, the association and desorption steps (R5 and R6) are pure chemical reaction and their kinetics is written in classical way (Eqs. (5) and (6)). The activity for all the surface species $i$ is given by the product of the number of available site on the LSCF surface $\Gamma$ and the surface coverage $\theta_{i}$ considering an ideal solution. In other words, a Langmuir isothermal hypothesis is adopted assuming a monolayer of adsorbed species on the LSCF surface without interaction:

$$
\theta_{O^{-}-s_{L S C F}}+\theta_{O-s_{L S C F}}+\theta_{O_{2}-s_{L S C F}}+\theta_{s_{L S C F}}=1
$$

where the subscripts $O^{-}-s_{L S C F}, O-s_{L S C F}$ and $O_{2}-s_{L S C F}$ denote the oxygen ad-ions, neutral ad-atoms and ad-molecules.

All the kinetics have been multiplied by the corresponding microstructural parameter in order to take into account the local geometry of the porous electrode. Therefore, the velocity for all the surface steps is dependent on the LSCF/gas specific surface area. The rate for the reaction R3 occurring at the gas, LSCF and CGO triple line is proportional to the TPBls density while the one for the ionic transfer R1 is scaled by the LSCF/CGO interfacial specific surface area. Finally, it is worth noting that all the reactions are supposed to be thermally activated. The 
kinetic constant $k_{i}$ in Table I are thus dependent on the temperature according to a classical Arrhenius' law:

$$
k_{i}=\mathrm{k}_{0, i} \exp \left(-\frac{E_{a c t, i}}{R T}\right)
$$

where $E_{a c t, i}$ is the activation energy for the reaction $i$.

Expressions for the mass and charge transfers - Regarding the transport phenomena, the fluxes of the surface species follow a classical Fick's law according to Eqs. (13-15) in Table II. The oxygen vacancies transport in the LSCF network (cf. Eq. (12)) is also expressed as a pure diffusional process through a chemical diffusivity depending on the oxygen partial pressure [59]:

$$
D_{\text {chem }}=-\frac{D_{V_{O}}}{2} \frac{\partial\left(\ln P_{O_{2}}\right)}{\partial\left(\ln C_{V_{o}}\right)}
$$

where $D_{V_{O}^{*}}$ is the oxygen vacancy self-diffusivity and $\frac{\partial\left(\ln P_{O_{2}}\right)}{\partial\left(\ln C_{\left.V_{O}^{*}\right)}\right.}$ is the thermodynamic factor. It is calculated using the dependence of the oxygen under-stoichiometry with the oxygen partial pressure measured in [60] by thermogravimetry on the studied $\mathrm{La}_{0.6} \mathrm{Sr}_{0.4} \mathrm{Co}_{0.2} \mathrm{Fe}_{0.8} \mathrm{O}_{3-\delta}$ compound.

The gas transport in the porosities is simulated in the frame of the dusty gas model (DGM) combining a molecular and Knudsen diffusion (Eq. (16)). The binary coefficient $D_{\mathrm{O}_{2}, \mathrm{~N}_{2}}$ for the molecular diffusion is expressed according to Fuller's Theory while the Knudsen coefficient $D_{k, O_{2}}$ is proportional to the mean pore radius $\bar{r}_{\text {pores }}$ :

$$
\begin{gathered}
D_{O_{2}, N_{2}}=\frac{0.00143}{P_{\text {tot }} \cdot\left(\left(V_{O_{2}}\right)^{1 / 3}+\left(V_{N_{2}}\right)^{1 / 3}\right)^{2} \cdot \sqrt{\frac{1}{\frac{1}{M_{O_{2}}}+\frac{1}{M_{N_{2}}}}}} \cdot T^{1.75} \\
D_{k, O_{2}}=\bar{r}_{\text {pores }} \cdot \frac{2}{3} \sqrt{\frac{8 \cdot R T}{\pi M_{i}}}
\end{gathered}
$$

where $M_{i}$ is the molar mass for the gas species and $V_{i}$ the Fuller diffusion volume tabulated in $[61]$. 
Finally, the ionic and electronic currents obey to the classical Ohm's law for LSCF and CGO in the electrode (Eqs. (11) and (17)) and for the CGO barrier layer as well (Eq. (18)). To account for the effect of microstructure in the electrodes, the intrinsic diffusivities and conductivities are corrected by the ratio of the phase volume fraction to the tortuosity factor to express the effective properties $\left(D_{i}^{e f f}=\left(\varepsilon_{i} / \tau_{i}\right) D_{i}\right.$ and $\left.\sigma_{i}^{e f f}=\left(\varepsilon_{i} / \tau_{i}\right) \sigma_{i}\right)$.

All the surface and oxygen vacancies diffusions together with the ionic conduction in CGO are supposed to be thermally activated and expressed using an Arrhenius' law. The temperature dependence for the LSCF electronic conduction has been neglected while its evolution with the oxygen partial pressure has been taken into account in the model as follows [30]:

$$
\sigma_{h_{L S C F}^{\cdot}}=\sigma_{0}\left(P_{O_{2}}\right)^{n}
$$

where $n$ is an exponent that can depend on the $P_{O_{2}}[62]$.

A set of mass and charge balance equations (Tab. II) was written for each species in the electrode and in the electrolyte. Each equation is formed by source/sink terms that consider the reaction rates for which the species is formed (positive sign) or consumed (negative sign). Moreover, a transient term is added to allow simulating the time-dependent response of the electrode. For the vacancies in LSCF and the adsorbed species, this temporal term is associated to the transient storage in the considered phase (Eqs. (20-24)). Regarding the charge balance for the ionic and electronic currents, the temporal term is related to the charging/discharging effect of the capacitor associated to the double layer at the LSCF/CGO interface (Eqs. (19) and $(25))$.

Lastly, the impact of the gas conversion in the EIS diagrams was also considered in the model. For this purpose, the gas channel is modeled as a Continuous Stirred Tank Reactor (CSTR) for which the inlet and outlet fluxes are linked according to the following mass balance $[49,63]$ :

$$
V_{C S T R} \frac{d C_{O_{2}}(z=\ell)}{d t}=F_{\text {Tot }}^{\text {inlet }} \cdot y_{O_{2}}^{\text {inlet }}(z=\ell)-F_{\text {Tot }}^{\text {outlet }} \cdot y_{O_{2}}(t, z=\ell) \pm\left|\vec{N}_{O_{2}}(t, z=\ell)\right| \times S_{e l} \text {. }
$$

where $\left|\vec{N}_{O_{2}}(t, z=\ell)\right|$ is the oxygen flux taken at the top of the electrode while $V_{C S T R}$ represents the volume of the CSTR. The terms $F_{\text {Tot }}^{\text {inlet }}$ and $F_{\text {Tot }}^{\text {outlet }}$ denote the inlet and outlet fluxes for the gas channel, respectively. In the chosen model, these terms have been assumed independent of time and calculated using the stationary version of the model (i.e. $F_{\text {Tot }}^{\text {outlet }} \cdot y_{O_{2}}(z=\ell)=F_{\text {Tot }}^{\text {inlet }}$. $\left.y_{O_{2}}^{\text {inlet }}(z=\ell) \pm\left|\vec{N}_{O_{2}}(z=\ell)\right| \times S_{e l}\right)$ [48]. It is worth noting that this approach can be considered valid only if the concentration overpotentials are limited (that is to say at OCP or under small 
dc current with a high inlet oxygen flux as considered in the experiments). Otherwise, a 2D model description constituted by a series of electrodes slices would be required to account the oxygen partial pressure evolution along the electrode length [63].

\subsection{Thermodynamic description}

In the model, the forward and backward kinetic constants for each reaction are linked through the thermodynamic equilibrium constant according to the set of equations reported in Table III. In Eq. (33), it can be noticed that the superficial potential step at equilibrium $\chi^{e q}$ is proportional to the coverage rate of the oxygen ions at equilibrium $\theta_{O^{-}-s_{L S C F}}^{e q}$ according to Eq. (7) (i.e. $\left.\chi^{e q}=\left(\Gamma F \theta_{O^{-}-s_{L S C F}}^{e q}\right) /\left(C_{d l}^{\text {surface }}\right)\right)$ [45]. Moreover, the electrode potential at equilibrium $E^{e q}$ in Eqs. (32) and (34) is equal to the chemical potential of oxygen in the gas phase taken at the reference electrode (i.e. $E^{e q}=\frac{\tilde{\mu}_{O_{2}(g a s)}^{r e f}}{4 F}$ knowing that $\left.E_{W E}^{e q}(V / R e f) \approx 0[64]\right)$.

In the present work, the equilibrium constants were not directly calculated from the thermodynamic data since there is still a large uncertainty on the entropies and enthalpies especially for the attached species on $\operatorname{LSCF}[48,65]$. As a consequence, the surface coverage at equilibrium $\left(\theta_{O^{-}-s_{L S C F}}^{e q}, \theta_{O-s_{L S C F}}^{e q}\right.$ and $\left.\theta_{O_{2}-s_{L S C F}}^{e q}\right)$ were considered as model inputs parameters at $P_{O_{2}}=0.21 \mathrm{~atm}$ and thus fitted using the dc experimental data. Furthermore, they were supposed to be independent on the temperature. This last assumption is rather well justified considering the low surface coverage assumed in Eq. (7) by neglecting the surface site restriction. Once the surface coverage of the three adsorbed species fitted at $P_{O_{2}}=0.21 \mathrm{~atm}$, the thermodynamic constants for the surface reactions $K_{e}^{(4)}, K_{e}^{(5)}$ and $K_{e}^{(6)}$ were determined.

To compute the composition at equilibrium, the concentration of oxygen vacancies $C_{V_{o}^{\prime \prime}}{ }^{e q}$ was determined as a function of the temperature and the oxygen partial pressure using the oxygen under-stoichiometry $\delta$ and the pseudo cubic lattice parameter for $\mathrm{La}_{0.6} \mathrm{Sr}_{0.4} \mathrm{Co}_{0.2} \mathrm{Fe}_{0.8} \mathrm{O}_{3-\delta}$ taken from Bouwmeester et al. [60] and Hashimoto et al. [66], respectively. Besides, using the previously determined constants $K_{e}^{(4)}, K_{e}^{(5)}$ and $K_{e}^{(6)}$, the system of Eqs. (35-37) were solved numerically to compute the evolutions of $\theta_{O^{-}-s_{L S C F}}^{e q}, \theta_{O-s_{L S C F}}^{e q}$ and $\theta_{O_{2}-s_{L S C F}}^{e q}$ as a function of the oxygen partial pressure.

Finally, the determination of the thermodynamic constants $K_{e}^{(1)}, K_{e}^{(2)}$ and $K_{e}^{(3)}$, involving bulk species, were calculated with Eqs. (32-34) using the data at equilibrium. 


\subsection{Boundary conditions and input parameters}

The thermodynamic computation allows obtaining the equilibrium constants used to express the backward kinetic constants and the composition at equilibrium used as initial values for the time dependent simulations. For the kinetic computation, the charge and mass balances (Eqs. (19-26) and (31)) combined with the expressions for the fluxes (Eqs. (11-18)) and the reaction rates (Eqs. (1-6)) constitute a set of Partial Differential Equations (PDEs) which are solved in the time domain by Finite Element Method (FEM). The methodology for the calculations of the EIS diagrams has been already described in [39].

For a sake of clarity, the boundary conditions are only summarized hereafter for the LSFCCGO composite electrode model. On the one hand, the ionic current is imposed in the barrier layer and is nil at the top of the electrode: $i_{i o}(z=0)=$ imposed; $i_{i o}\left(z=\ell_{C G O}+\ell\right)=0$. On the other, the electronic potential in LSCF is taken at zero at the top of the electrode while the electronic current is nil at the interface with the barrier layer: $\varphi_{e l}\left(z=\ell_{C G O}+\ell\right)=0$ $i_{e l}\left(z=\ell_{C G O}\right)=0$; . The flux of vacancies in LSCF is equal to zero on each side of the electrode: $\overrightarrow{\mathrm{N}}_{\mathrm{V}_{0} \cdot \cdot}\left(z=\ell_{C G O}\right)=\overrightarrow{\mathrm{N}}_{\mathrm{V}_{0} \cdot \cdot}\left(z=\ell_{C G O}+\ell\right)=0$ and the fluxes for all the adsorbed species on LSCF

are nil on each side of the electrode: $\overrightarrow{\mathrm{N}}_{i-S_{L S C F}}\left(z=\ell_{C G O}\right)=\overrightarrow{\mathrm{N}}_{i-S_{L S C F}}\left(z=\ell_{C G O}+\ell\right)=0$. Finally, the oxygen gas flux is imposed at the inlet of the gas channel and is nil at the barrier layer interface: $F_{O_{2}}^{\text {inlet }}\left(z=\ell_{C G O}+\ell\right)=$ imposed $; \vec{N}_{O_{2}}\left(z=\ell_{C G O}\right)=0$.

Regarding the input parameters for the simulations, all the microstructural properties were extracted from the 3D reconstructions (cf. section 4.1). The gas diffusivities were evaluated with Eqs. $(28,29)$ while the electronic conductivity in the LSCF was estimated with Eq. (30). In this case, the exponent $n$ was considered to vary from $n=+1 / 5$ to $n=1 / 20$ according to the data reported in [62]. The evolution of CGO ionic conductivity with the temperature was determined in the model using an activation energy of $65 \mathrm{~kJ} \cdot \mathrm{mol}^{-1}$ [67]. The oxygen vacancy self-diffusivity for LSCF was taken in order to obtain the same chemical diffusivity than the one used in [32] at $700^{\circ} \mathrm{C}$ under air with an activation energy of $156 \mathrm{~kJ} \cdot \mathrm{mol}^{-1}$. It can be noticed that these values are consistent with data reported in the literature $[60,68]$. The capacitance of the LSCF/CGO double layer was taken at $0.5 \mathrm{~F} \cdot \mathrm{m}^{-2}$ as estimated in [31]. For what concerns the surface capacitance $C_{d l}^{\text {surface }}$, a wide range of data spreading from $0.1 \mathrm{~F} \cdot \mathrm{m}^{-2}$ up to $100 \mathrm{~F} \cdot \mathrm{m}^{-2}$ is reported in the literature [49]. In the present model, a low value of $0.2 \mathrm{~F} \cdot \mathrm{m}^{-2}$ was chosen for the simulations to be consistent with the assumption of the low oxygen ions coverage at the LSCF 
surface. All the mentioned input parameters are provided in Tab. IV at the reference temperature of $700^{\circ} \mathrm{C}$ at $P_{O_{2}}=0.21 \mathrm{~atm}$.

In order to reduce further the number of unknown parameters, two supplementary assumptions have been considered. Firstly, as generally observed and admitted for the studied electrodes [69], the oxygen ionic transfer (R1) across LSCF/CGO interface was supposed as not limiting $\left(k_{+} \gg 0\right)$. In addition, the associative reaction (R5) on the LSCF surface was considered very fast and near the equilibrium as justified in [48] $\left(k_{\text {ass }} \gg 0\right)$.

Finally, the LSCF surface properties including the surface coverages at equilibrium at $P_{O_{2}}=0.21$ atm, the surface diffusivities and the kinetic constants for the surface reactions along with their related activation energies correspond to the missing input parameters fitted on the experimental data (cf. section 4.3: fitted properties listed in Table VI).

\section{Experimental results and model validation}

\subsection{Electrode 3D reconstructions and electrochemical characterizations}

The rendering volumes for the 3D reconstructions after segmentation are shown in Fig. 2 for the two studied electrodes. The LSCF, CGO and YSZ phases appear in blue, yellow and orange, respectively. At a first sight, it can be noticed that the microstructure for the two electrodes seems well representative of classical SOC electrodes. To confirm this claim, the microstructural properties have been computed on the reconstructions and the corresponding data are listed in Tab. V. As expected, all the values lie in the range of the properties reported for classical LSCF and LSCF/CGO electrodes $[70,71]$. The microstructure properties are used as input parameters for the model validation.

For the electrochemical characterizations, it is worth mentioning that all the results reported for the LSCF electrode have been obtained in the frame of the present study while the ones for the composite electrode have been already detailed in [32].

As a preliminary remark for the LSCF electrode, it is worth mentioning that a perfect superposition has been found between the impedance spectra for the WE and CE versus the RE (as shown in Fig. S1 given in the supplementary information). Therefore, it can be stated that the setup allows obtaining a quasi-ideal symmetry between the two LSCF electrodes, indicating the accuracy of the measurements. For this LSCF electrode, the experimental polarization 
curves measured at $750^{\circ} \mathrm{C}, 700^{\circ} \mathrm{C}$ and $650^{\circ} \mathrm{C}$ under air are shown in Fig 4a. The electrode overpotential is lowered with increasing temperature as it could be expected from a thermal activation of the electrode reaction mechanism for LSCF-based electrodes [31, 32, 72, 73]. Regardless of the operating mode (SOEC or SOFC), the evolution of the current density can be regarded as linear at all temperatures for electrode overpotentials below 0.05 V/air. An activation is evidenced for higher electrode overpotentials for temperatures up to $700{ }^{\circ} \mathrm{C}$. At $750{ }^{\circ} \mathrm{C}$, the polarization curve is symmetric and linear but it is likely to be due to the narrow overpotential range. These results are confirmed by the plot of the polarization resistance $R_{p}$ as a function of the current density $i$ (Fig. 4c-4e). Indeed, a strong dissymmetry of $R_{p}=f(i)$ is observed at $650^{\circ} \mathrm{C}$ that becomes less pronounced at $700^{\circ} \mathrm{C}$, while a constant value is found at $750^{\circ} \mathrm{C}$. These observations at $650^{\circ} \mathrm{C}$ may suggest a change either in the reaction mechanism or in the rate-determining steps. This change turns into a gradual transition at $700^{\circ} \mathrm{C}$ and, finally, into a unique dominant mechanism with the same co-limitations at $750^{\circ} \mathrm{C}$. However, as already mentioned in this case, the investigated range of current densities and overpotentials are restricted close to the equilibrium.

The EIS at OCP are plotted in the Nyquist representation in Fig. 5a to 5c. It is worth mentioning that the polarization resistance decreases with increasing the temperature in good agreement with the evolution of the polarization curves. Besides, all the diagrams present a kind of Gerischer-type element whatever the investigated temperature. It can be noticed that a small contribution appears at low frequencies for the diagram at $750^{\circ} \mathrm{C}$. This contribution is ascribed to the limitation associated to the gas conversion and it is typically observed for electrodes exhibiting a low polarization resistance at high temperatures [42]. As shown in the Bode plots reported in Fig. 5d to 5f, the characteristic frequency slightly increases with the operating temperature (i.e. $f_{c} \approx 12 \mathrm{~Hz}, 19 \mathrm{~Hz}$ and $34 \mathrm{~Hz}$ at $650^{\circ} \mathrm{C}, 700^{\circ} \mathrm{C}$ and $750^{\circ} \mathrm{C}$, respectively), in agreement with the variation recorded for a LSCF-CGO composite [32]. However, these values remain quite close to each other. To conclude, it can be stated that the unaffected shape of the impedance diagrams would suggest that the electrode is dominated at OCP by the same reaction mechanism in the range of studied temperatures.

The EIS under dc current density at $i_{d c}=+/-50 \mathrm{~mA} \cdot \mathrm{cm}^{-2}$ are shown in Fig. 6 a to $6 \mathrm{~d}$. As at OCP, the shape of the diagrams presents a kind of Gerischer-type element. The frequency distribution increases with increasing the dc current from cathodic to anodic polarization $\left(f_{c} \approx 7 \mathrm{~Hz}\right.$ at $i_{d c}=$ 
$-50 \mathrm{~mA} \cdot \mathrm{cm}^{-2}$ and $f_{c} \approx 24 \mathrm{~Hz}$ at $i_{d c}=+50 \mathrm{~mA} \mathrm{~cm}^{-2}$ ) as it has been already observed by Monaco et al. [31].

The same electrochemical characterizations have been performed for the LSCF-CGO electrode. As already mentioned, all the results have been already presented and discussed in [32]. For the model validation, the polarizations curves at $650^{\circ}, 700^{\circ} \mathrm{C}$ and $750^{\circ} \mathrm{C}$ are shown in Fig. $4 \mathrm{~b}$ while the EIS diagrams are reported in the supplementary. As a brief summary, the polarization curves have been found symmetric at $700^{\circ} \mathrm{C}$ and $750^{\circ} \mathrm{C}$ whereas a dissymmetry appears at the lowest operating temperature $\left(650^{\circ} \mathrm{C}\right)$. Moreover, all the EIS diagrams exhibit a Gerischer-type impedance. It can be remarked that the performances of the LSCF-CGO composite is lower than the LSCF electrode, which is contradictory with our previous statement in [32]. However, in this case, the performance of the two electrodes cannot be directly compared. Indeed, the two type of electrodes exhibit very different microstructures since they were produced using different manufacturing conditions.

Finally, in complementarity with the previous characterizations, a specific attention has been paid in this work to study the effect of the oxygen partial pressure on the LSCF and the LSCFCGO electrodes response. The evolution of the impedance diagrams at OCP are given in Fig 7a and $7 \mathrm{~b}$ for oxygen partial pressures ranging from 0.1 to $1 \mathrm{~atm}$. It can be noticed that the electrode polarization resistance significantly decreases when increasing the oxygen content, as already experimentally observed in $[49,74,75]$. The reaction order $m$ was estimated fitting the experimental data with the following relation:

$$
R_{\text {pol }}=\left(P_{O 2}\right)^{-m}
$$

where $R_{p o l}$ is the polarization resistance extracted from the EIS at OCP (measured as the difference of the intercepts with the real axis at high and low frequencies).

In Fig. 7c, the results are plotted in logarithmic coordinates for the LSCF electrode. A slight evolution of the slope is found with an exponent decreasing from 0.17 for $0.10 \mathrm{~atm} \leq P_{\mathrm{O}_{2}} \leq$ $0.21 \mathrm{~atm}$ down to 0.09 for $P_{O_{2}}>0.21 \mathrm{~atm}$. These reaction orders are in rather good agreement with literature data. For instance, an exponent of 0.12 was deduced for a LSCF nanorod electrode operated at $717{ }^{\circ} \mathrm{C}$ in a range of oxygen partial pressure $P_{O_{2}} \in\left[\begin{array}{lll}0.10 & -0.20\end{array}\right]$ atm [75]. For the LSCF-CGO composite, the evolution of the slope in Fig. $7 \mathrm{~d}$ is less pronounced than for the LSCF electrode. In this case, the exponent decreased from 0.20 for 0.10 atm $\leq P_{\mathrm{O}_{2}} \leq$ 
$0.21 \mathrm{~atm}$ down to 0.15 for $P_{O_{2}}>0.21 \mathrm{~atm}$. Very few data are available in the literature for the composite electrode. To the best of our knowledge, no values are reported for an operating temperature close to $700^{\circ} \mathrm{C}$. Nevertheless, Murray et al. [76] found a reaction order of 0.13 for a LSCF-CGO (40-60 wt. \%) at $750^{\circ} \mathrm{C}$ for $6.00 \cdot 10^{-4} \mathrm{~atm} \leq P_{O_{2}} \leq 1.00 \mathrm{~atm}$. Besides, Hughes et al. [74] have reported a value of 0.20 for LSCF-CGO (50-50 wt. \%) at $600^{\circ} \mathrm{C}$ between 0.10 and $10 \mathrm{~atm}$. Although these values were determined in different operating conditions, they are roughly consistent with the ones obtained in the present study.

\subsection{Model calibration}

The model unknown parameters detailed in section 3.4 were determined by fitting the simulated data on the experimental electrode polarization curves at the three investigated temperatures. In other words, the computed $i-\eta$ curves have been adjusted on the experimental data through an iterative process. Because of the nonsymmetrical shape of the electrode response (especially at $700^{\circ} \mathrm{C}$ and $650^{\circ} \mathrm{C}$ ), it is worth mentioning that this process has led to determine a unique value for each of the missing parameters. The results of the fitting procedure are shown in Fig. $4 \mathrm{a}$ and in Fig. $4 \mathrm{~b}$ for the LSCF and LSCF-CGO electrodes, respectively. As expected, the calibrated model is able to simulate accurately the shape of the measured $i-\eta$ curves at each operating temperature for both studied electrodes. Indeed, for the LSCF electrode, the fitting procedure led to obtain a root-mean square deviation of $0.014,0.0015$ and 0.006 at $650^{\circ} \mathrm{C}, 700^{\circ} \mathrm{C}$ and $750^{\circ} \mathrm{C}$, respectively. For the LSCF-CGO composite, the root-mean square deviation was found equal $0.017,0.0028$ and 0.0048 at $650^{\circ} \mathrm{C}, 700^{\circ} \mathrm{C}$ and $750^{\circ} \mathrm{C}$, respectively.

All the model fitted parameters are reported in Tab. VI. Firstly, it can be noticed that low values were obtained for the surface coverage at equilibrium (for $P_{O_{2}}=0.21 \mathrm{~atm}$ ) in good agreement with the assumption of a diluted solution considered for Eq. (7). Moreover, the activation energies for the diffusivities and kinetic constants are quite consistent between the two electrodes. Indeed, a good agreement is found for these fitted parameters with a mismatch of less than $18 \%$ except for the activation energy associated to the charge transfer at TPBls. In this case, the difference increases up to $39 \%$. Besides, the diffusion coefficients as well as the kinetic constants for the oxygen ionization and adsorption, which are reported in Table VI at $700^{\circ} \mathrm{C}$, are also coherent between the two investigated electrodes. However, a discrepancy was found for the excorporation kinetic constant. This unexpected result could be explained by different surface states for LSCF in the two types of electrode affecting the reaction of 
excorporation/incorporation. Finally, it can be noticed that the kinetic constants for the charge transfer at TPBls cannot be compared since they do not have the same dimension. As a general matter, in spite of some differences, it can be claimed that the parameters fitted on the i- $\eta$ curves are consistent between the LSCF and LSCF-CGO electrodes.

\subsection{Model validation}

\subsubsection{Impedance diagrams}

In order to validate the model, impedance diagrams were computed in the same conditions of the experiments without any additional fitting. The comparison between the simulated and measured EIS for the LSCF electrode at OCP is reported in Fig. 5. From the diagrams represented in the Nyquist plot in Fig. $5 \mathrm{a}$ and $5 \mathrm{~b}$ at $650^{\circ} \mathrm{C}$ and $700^{\circ} \mathrm{C}$, it can be seen the model is able to predict quite accurately the shape of the experimental EIS characterized by a kind of Gerischer type-element. For instance, the root-mean square deviation for the LSCF impedance at $700^{\circ} \mathrm{C}$ and $\mathrm{OCP}$ is equal to 0.007 . It is worth noting that the agreement between experimental and simulated impedance diagrams in the low frequency range at high temperature (Fig. 5c) suggests that the CSTR model (Eq. (31)) is well adapted to capture the effect of gas conversion that appears at $750{ }^{\circ} \mathrm{C}$. In Fig. 6, the impedance diagrams recorded under polarization are compared to the simulated ones at $700^{\circ} \mathrm{C}$. As shown in Fig. $6 \mathrm{a}$ and $6 \mathrm{~b}$ for the Nyquist plots, the model is also able to reproduce quite correctly the global shape of the impedance diagrams under cathodic and anodic polarizations. It can be noticed that, in the range of investigated polarizations, the EIS still exhibit a Gerischer type-element behavior suggesting that the LSCF electrode mechanism remains unchanged in these operating conditions.

The computed and experimental frequency distributions are compared at $\mathrm{OCP}$ in Fig. $5 \mathrm{~d}$ to $5 \mathrm{f}$ and under polarization at $700^{\circ} \mathrm{C}$ in Fig. $6 \mathrm{c}$ and $6 \mathrm{~d}$ for the diagrams plotted in the Bode plan. It can be observed that the increase of the characteristic frequency with the temperature and the polarization is well retrieved with the model. This evolution of the characteristic frequency at OCP with the temperature and under polarization at $700^{\circ} \mathrm{C}$ is explained by a higher contribution of the surface path as detailed in section 5. Nevertheless, a frequency lag between the simulations and the measurements is obtained for all the diagrams. Indeed, the computed frequency distribution is systematically lower than the experimental one. The precise origin of this frequency shift is still unclear. The disagreement may come from an uncertainty on the 
determination of the microstructural properties using a 3D reconstruction that could be not fully representative of potential inhomogeneities in the whole electrode volume. Indeed, the electrode microstructure can play a major role on the frequency response of the electrode [42, 77, 78]. Moreover, it could be also mentioned that even a slight change in the bulk to surface ratio for the reaction mechanism could have a strong impact on the simulated frequency distribution as discussed in section 5.1. Besides, the experimental conditions could affect the measurements of the frequency distribution partially explaining the discrepancy between the simulations and the experimental data.

The comparison for the experimental and simulated impedance diagrams for the LSCF-CGO electrode are reported in the supplementary information (Fig.S2 and Fig. S3) It is worth mentioning that the same results than the LSCF electrode have been obtained for this composite material, i.e. the model is also able to reproduce correctly the shape of the experimental impedance diagrams whatever the temperature or the polarization. All the evolutions of the frequency distribution with the operating conditions are also well retrieved with the model even though a frequency shift is also observed for the composite electrode. To conclude, despite the systematic error on the frequency distribution, it can be asserted that, without supplementary fitting, the model is able to predict quite correctly the impedance response for the two types of studied electrodes.

\subsubsection{Effect of the oxygen partial pressure}

To go further in the model validation, its capability to simulate the dependency of the electrode response with the oxygen partial pressure has been investigated for both studied electrodes. For this purpose, impedance diagrams at OCP have been computed changing the oxygen content in the gas (without fitting). The graphs of $R_{p o l}$ as a function of $P_{O_{2}}$ have been plotted in logarithmic coordinates and compared to the experimental data in Fig. 7c and Fig. 7d for the LSCF and LSCF-CGO electrodes, respectively. In the two cases, it can be seen that the model predicts accurately the gradual increase of the polarization resistance when decreasing the oxygen partial

pressure. Moreover, the model also captures correctly the higher dependency with $P_{\mathrm{O}_{2}}$ for the LSCF electrode compared to the composite one. A slight distortion of the low frequency part of the impedance diagram recorded for the LSCF electrode at $700{ }^{\circ} \mathrm{C}$ can be detected at low $P_{O_{2}}$ values (Fig. 7a), as it was evidenced at $750{ }^{\circ} \mathrm{C}$ under air (Fig. 5c). This contribution was also 
observed by Mosialek et al. [79] in the same experimental conditions confirming that a gas conversion impedance arises also at low oxygen partial pressures.

This good agreement between the model and the experiments is also confirmed by the reaction order $m$ drawn from the simulated data for both studied electrodes. Regarding the LSCF electrode, the fitted value was found equal to 0.15 for $0.10 \mathrm{~atm} \leq P_{O_{2}} \leq 0.21$ atm and to 0.09 for $P_{\mathrm{O}_{2}}>0.21 \mathrm{~atm}$ (Fig. 7c). For the LSCF-CGO electrode, a fitted value of 0.27 was calculated for $0.10 \mathrm{~atm} \leq P_{\mathrm{O}_{2}} \leq 0.21 \mathrm{~atm}$ while a value of 0.16 was obtained for $P_{O_{2}}>0.21 \mathrm{~atm}$ (Fig. 7d). All these exponents are very close to the ones fitted on the experimental data (cf. section 4.1). For instance, the error on the reaction orders for the LSCF electrode is less than $12 \%$. The consistency between the experimental and computed exponents would indicate the relevance of the model assumption regarding the reaction mechanism and the presence of oxygen ions on the LSCF surface. Therefore, as pointed out by Fleig et al. [46], the description of the reaction mechanism with elementary reactions in the porous electrode allows the good prediction of the electrode response as a function of the $P_{O_{2}}$.

As a general comment, it was possible using the same model to reproduce the polarization curves for the LSCF and LSCF-CGO electrodes by identifying for the two cases a set of consistent data (kinetic constants and surface diffusivities). Moreover, the model is able to predict without any fitting the LSCF and LSCF-CGO electrodes behavior with the change of $P_{\mathrm{O}_{2}}$ and the shape of the impedance diagrams depending on the temperature and polarization. In spite of a systematic frequency lag in the impedance spectra, the capacity of the model to reproduce the response for the two types of electrodes allows validating the main model assumptions.

\section{Discussion}

\subsection{Study of the reaction mechanism as a function of the temperature, polarization and oxygen partial pressure}

Effect of polarization and temperature on the reaction pathway under air condition - To study the reaction pathway under air at the three studied temperatures, the ratio of the surface to the 
bulk path has been computed as a function of the current density for LSCF (Fig. 8a) and LSCFCGO (Fig. 8b), respectively. The ratio is defined by the integration of R3 and R2 over the electrode thickness for the LSCF-CGO composite, while R3 is limited at the electrolyte interface for the LSCF electrode.

For both electrodes, this ratio is an increasing function of the anodic current, regardless of the operating temperature (Fig. 8). This behavior is associated to the concentration of the oxygen vacancies in the LSCF material. Indeed, as already discussed in $[30,39]$, the LSCF understoichiometry tends to zero by increasing the anodic polarization. In this condition, the bulk path becomes more and more limited, while the direct oxidation at the TPBls is promoted (without limitation due to the accumulation of adsorbed oxygen species on the LSCF since the surface coverage of the adsorbed oxygen species at equilibrium is low). This evolution is illustrated for the LSCF electrode in Fig. 8c by plotting the kinetic rates of both the charge transfer at TPBls and the oxygen incorporation/excorporation (integrated along the electrode thickness). Accordingly, the reaction of oxygen excorporation becomes bounded under anodic polarization while the charge transfer at TPBls is strongly activated. On the contrary, an opposite behavior is highlighted under cathodic polarization (i.e. the incorporation step is activated while the reaction at TPBls is bounded). As already shown for the LSCF electrode [31], a transition from the bulk to the surface path occurs by increasing the anodic polarization at all the operating temperatures (Fig. 8a). Even if a slight increase of the ratio is detected as a function of the operating temperature, the bulk path appears to be the dominant pathway for the LSCF electrode at OCP (Fig. 8a). This result is in good agreement with the Gerischer typeelement observed for the diagrams obtained in this condition [80] (Fig. 5). Moreover, a steep variation of the ratio is found at $650^{\circ} \mathrm{C}$ indicating a well-defined threshold for the transition from the bulk to the surface path. However, this evolution and the transition become smoother by increasing the operating temperature (Fig. 8a). This behavior is in accordance with the derivatives of the polarization curves as a function of the current density. Indeed, a clear dissymmetry occurs close to the OCP at $650^{\circ} \mathrm{C}$ (Fig. 4c), while a more linear evolution is observed at $750^{\circ} \mathrm{C}$ (Fig. 4e). From the analysis of the ratio at $750^{\circ} \mathrm{C}$ (Fig. 8a), it can be stated that the constant value measured experimentally is due to the fact that the investigated range of current density is not sufficiently extended to detect the transition to the surface path (taking place at a higher anodic dc current $\approx+200 \mathrm{~mA} \cdot \mathrm{cm}^{-2}$ ). At $700^{\circ} \mathrm{C}$, the ratio starts to be higher than the unity only at $\approx+90 \mathrm{~mA} \cdot \mathrm{cm}^{-2}$ (Fig. 8a). This result explains why no change in the impedance 
diagrams was observed since the experiments were conducted for a lower dc current $( \pm 50$ $\mathrm{mA} \cdot \mathrm{cm}^{-2}$ : cf. section 4.1$)$.

The ratio has also been computed at $800^{\circ} \mathrm{C}$ for the LSCF electrode taking advantage of the fitted activation energies. As it can be noticed in Fig. 8a, the ratio increases very slowly with the current density, probably due to the small overpotential values. Thereby, the transition to the surface path is much less abrupt and it is decayed at high anodic current density $\left(\approx 300 \mathrm{~mA} \cdot \mathrm{cm}^{-}\right.$ ${ }^{2}$ ). This result may explain the apparent discrepancy between our statements and the conclusions of Ma et al. [40] who claimed that the LSCF remains dominated by the bulk path in both anodic and cathodic polarizations at $800^{\circ} \mathrm{C}$. Furthermore, it is worth noting that in their model, the chemical diffusivity depends exponentially on the concentration of oxygen vacancies in the $\operatorname{LSCF}\left(D_{\text {chem }}=A \exp \left(B\left(C_{V_{o}^{*}}-C_{V_{o}^{*}}^{e q}\right)\right)\right)$. With this model, the steep increase of $D_{\text {chem }}$ at the electrolyte interface prevents the limitation of the bulk path under anodic current. In our case, the dependence of the chemical diffusivity with the concentration of vacancies is given by the thermodynamic factor computed using the local oxygen partial pressure in the electrode and the thermogravimetric data from [60] (cf. Eq. (27)). With this approach, the chemical diffusivity increases only slightly on the investigated range of oxygen partial pressure (i.e. $P_{\mathrm{O}_{2}} \geq 0.10 \mathrm{~atm}$ ). This evolution is in good agreement with several articles that have referred only a very slight evolution of $\mathrm{D}_{\text {chem }}$ for $P_{O_{2}} \geq 0.10 \mathrm{~atm}[30,59,62,60,68]$.

As shown in Fig. 8b, the reaction mechanism for the LSCF-CGO electrode is completely dominated by the surface path whatever the polarization at $750^{\circ} \mathrm{C}$ and $700^{\circ} \mathrm{C}$. This result could have been anticipated since the surface pathway is favored by the multiplication of the active sites in the whole electrode volume. However, the reaction mechanism starts to be fully controlled by the bulk path under low cathodic overpotentials when the temperature is lowered down to $650^{\circ} \mathrm{C}$ (Fig. 8b). This change in the reaction pathway is also experimentally confirmed by the dissymmetric shape of the i- $\eta$ curve recorded at $650^{\circ} \mathrm{C}$ (Fig. $4 \mathrm{~b}$ ). All these results deduced from the present elementary model are fully consistent with the analysis reported in [32] using the simplified version of the model (taking into account only the presence of adsorbed neutral oxygen atoms on the LSCF surface). 
Impact of the ratio on the impedance response - Impedance spectra have been computed below and above the transition at $700^{\circ} \mathrm{C}$ under air for $i_{d c}=+50,+90,+120$ and $+150 \mathrm{~mA} \cdot \mathrm{cm}^{-2}$ to gain insight on the effect of the predominant reaction path on the electrode impedance response. The corresponding diagrams plotted in the Nyquist and Bode plans are given in the supplementary (Fig. S4). A change in the shape of the diagram has been highlighted with an evolution starting from a slightly depressed Gerisher type-element towards a complete flattened semi-circle at $i_{d c}=+150 \mathrm{~mA} \cdot \mathrm{cm}^{-2}$. This evolution is in good agreement with the experimental results reported in [31]. Furthermore, a sharp increase of the characteristic frequency has been found when the dc current is raised above the threshold (at around $+90 \mathrm{~mA} \cdot \mathrm{cm}^{-2}$ ). Indeed, the apex frequency is augmented from $0.7 \mathrm{~Hz}$ at $i_{d c}=+50 \mathrm{~mA} \cdot \mathrm{cm}^{-2}$ up to $13 \mathrm{~Hz}$ at $i_{d c}=+150 \mathrm{~mA} \cdot \mathrm{cm}^{-2}$ (with $1.9 \mathrm{~Hz}$ and $4.9 \mathrm{~Hz}$ for the intermediate values corresponding to $+90,+120 \mathrm{~mA} \cdot \mathrm{cm}^{-2}$, respectively). This statement shows that the simulated frequency distribution is strongly impacted even by a slight change in the ratio of the surface to bulk path for the reaction mechanism. Therefore, the mismatch between the computed and experimental frequencies highlighted in section 4.3.1 could be partly due to a slight under-estimation of the surface path in the modeling results.

Effect of oxygen partial pressure on the reaction mechanism at $O C P$ - Taking advantage of the elementary model capability to predict the electrode response depending on $P_{\mathrm{O}_{2}}$, the effect of oxygen partial pressure on the reaction mechanism for the LSCF electrode has been investigated at OCP. For this purpose, simulations have been carried out at $700^{\circ} \mathrm{C}$ changing step by step the oxygen partial pressure from $P_{O_{2}}=0.1 \mathrm{~atm}$ to $1 \mathrm{~atm}$. As shown in Fig. 9a, the increase of oxygen content in the gas phase enhances gradually the contribution of the surface path in the reaction mechanism. For instance, the ratio of the surface path to the bulk path close to the OCP rises from 0.29 at $P_{O_{2}}=0.1$ atm up to 1.05 at $P_{O_{2}}=1$ atm (Fig. 9a). On the one hand, this evolution can be explained by the decrease of the LSCF under-stoichiometry at equilibrium when the oxygen partial pressure is increased. As for an anodic polarization, the low concentration of vacancies at high oxygen partial pressure tends to block the bulk path towards a lower bound (Fig. 9b). As expected, the integrated reaction rate of oxygen incorporation/excorporation (R2) is a decreasing function of the oxygen partial pressure. On the other hand, the increase of $P_{O_{2}}$ also leads to enhance the oxygen activities for the adsorbed species promoting the reaction kinetics involved in the surface path. This statement is illustrated in Fig. $9 \mathrm{~b}$ by the continuous increase of the rate of charge transfer at TPBls (R3) with the oxygen partial pressure. As a result, it can be noticed in Fig. $9 \mathrm{~b}$ that the sum of the two contributions increases with $P_{O_{2}}$ 
explaining the continuous decrease of the electrode polarization resistance as previously discussed (cf. sections 4.1 and 4.3.2). It can be mentioned that the same explanation stands for the LSCF-CGO electrode. Nevertheless, the promotion of the reactions involved in the surface path is less sensitive to oxygen activities on the surface since, in this case, there is not a limitation in the density of available TPBls for the reaction step R3. Therefore, the improvement of the electrode performances with the oxygen partial pressure is less pronounced than for the LSCF electrode. Indeed, the ratio of the surface path to the bulk path rises at OCP only by a factor of 2.2 for the LSCF-CGO electrode when $P_{O_{2}}$ varies between 0.1 and 1 atm at $700{ }^{\circ} \mathrm{C}$ (see supplementary, Fig. S5).

To identify the rate-determining steps for the LSCF electrode at OCP, a sensitivity analysis has been conducted with the model changing the kinetic constant one after the other. The impedance simulations have been performed at $700^{\circ} \mathrm{C}$ for two oxygen partial pressures at $P_{O_{2}}=0.15$ and $0.30 \mathrm{~atm}$. For the chosen conditions, the ratio of the surface path to the bulk path is equal to 0.39 and 0.58 , respectively (Fig. 9a). For both oxygen partial pressures, it has been found that the adsorption R6 and ionization R4, which belong to the common path, co-limits the reaction mechanism. Indeed, the division by two of their respective kinetic constants leads to raise significantly the polarization resistance, i.e. the relative increase of the polarization resistance $\Delta R_{\text {pol }} / R_{\text {pol }}$ is found equal to $8 \%$ (resp. $6 \%$ ) for $k_{\text {ads }} / 2$ and to $14 \%$ (resp. $11 \%$ ) for $k_{i o n} / 2$ at $P_{O_{2}}=0.15 \mathrm{~atm}$ (resp. $0.30 \mathrm{~atm}$ ). When the mechanism is dominated by the bulk path at low oxygen partial pressure, the reaction of oxygen incorporation/excorporation (R2) is identified as an additional rate-determining step whereas the role of the reaction at TPBls (R3) becomes more and more negligible. Indeed, the division by two of their kinetic constants yields an

increase of $R_{p o l}$ of $17 \%$ for $k_{o x}^{L S C F / g a s} / 2$ and $5 \%$ for $k_{o x}^{T P B l s} / 2$. As expected, this result tends to be reversed when increasing the oxygen partial pressure to $0.3 \mathrm{~atm}$. In that case, the diminution of the electrode performances due to the decrease of $k_{o x}^{L S C F / g a s}$ is of $15 \%$ whereas it reaches almost $10 \%$ when reducing the charge transfer at TPBls. In this case, the reaction mechanism becomes also more and more dependent on the surface diffusion coefficient of the oxygen ions (hindering the oxygen transport away from the TPBls restricted at the electrolyte interface).

\subsection{Impact of the LSCF decomposition on the electrode performances}

As mentioned in the introduction, the LSCF decomposition upon operation is liable to decrease global exchange kinetic constant $k_{\text {chem }}$ due to the LSCF surface passivation. Besides, the loss 
of strontium can affect the chemical diffusivity by modifying the oxygen stoichiometry in the bulk of the material. To date, few data are reported in the literature to estimate the decay of $k_{\text {chem }}$ and $D_{\text {chem }}$ due to the demixing for the classical $\mathrm{La}_{0.6} \mathrm{Sr}_{0.4} \mathrm{Co}_{0.2} \mathrm{Fe}_{0.8} \mathrm{O}_{3-\delta}$ compound. Wang et al. [81] have estimated a decrease of $D_{\text {chem }}$ and $k_{\text {che }}$ of $50 \%$ after an isothermal ageing of symmetric cells at $800{ }^{\circ} \mathrm{C}$ for 800 hours. However, the same authors have also reported a decrease of around $85 \%$ for $k_{\text {che }} \quad$ with no significant change in $D_{\text {chem }}$ for LSCF electrodes annealed at $700-800^{\circ} \mathrm{C}$ for the same period [23]. In addition, Kim et al. [22] have found a severe decrease of $k_{\text {chem }}$ estimated to $85 \%$ whereas the deviation in the chemical diffusivity is only of $8 \%$ for sintered LSCF pellets after a thermal ageing at $800^{\circ} \mathrm{C}$ for 800 hours. For an ageing at $750^{\circ} \mathrm{C}$ during 1012 hours using complete cells, Endler-Schuck et al. [82] have found that the 'performance degradation in the LSCF electrode seems to be caused by a decrease of the bulk diffusion while the exchange coefficient remains almost constant'. At $600^{\circ} \mathrm{C}$, they have found that both parameters decrease with the ageing time. Therefore, there is still a large uncertainty on the real impact of the LSCF demixing on the values of $D_{\text {chem }}$ and $k_{\text {chem. }}$. Wang et al. [23] have proposed that this apparent discrepancy could be explained by a potential slight deficiency on the A-site of the perovskite that could lead to different Sr segregation. Furthermore, it can be suspected that the experimental conditions such as the presence of residual steam in the gas stream may also influence the results.

In spite of this scattering of the published results, the elementary model has been used to assess the impact of the LSCF demixing on the electrode response. Firstly, the electrode surface passivation was simulated by decreasing the specific surface area between the LSCF and the gas phase $\left(S_{p}^{L S C F / g a s}\right)$. Indeed, the kinetics of the surface reactions for the common path as well as the reaction of oxygen incorporation/excorporation (R2) for the bulk path are proportional to this parameter (cf. Table I). It is worth noting that the combination of all these reaction kinetics results in the global exchange kinetic constant $k_{c h e m}$ usually estimated at OCP according to the 'ALS' model $[23,81,82]$. Secondly, the loss of ionic conductivity due to the $\mathrm{Sr}$ release from the perovskite lattice was simulated by decreasing the oxygen chemical diffusivity $\left(D_{\text {chem }}\right)$. The sensitivity analysis was carried out for the LSCF electrode computing the impedance diagrams at $750^{\circ} \mathrm{C}$ under air at OCP and for a dc current of $\pm 50 \mathrm{~mA} \cdot \mathrm{cm}^{-2}$. The electrode degradation was simulated by decreasing each parameter by $10 \%$ up to $50 \%$. This range was chosen since a decrease of $10 \%$ can be roughly seen as a lower bound for the degradation, while a decrease of $50 \%$ remains in the scale of the reasonable published values. Finally, it can be mentioned that the bulk path is prevailing in the chosen conditions for the 
simulations. Indeed, the bulk path must be favored to determine the effect of the oxygen chemical diffusivity on the polarization resistance.

Degradation at $O C P$ - The evolution of the impedance diagrams and frequency distribution in the Nyquist and Bode plots are respectively shown in Fig. 10a and 10b as a function of the surface passivation at $\mathrm{OCP}$. An enlargement of the spectra for the contribution at low frequencies is found (Fig. 10a), which is accompanied by a slight shift of the frequency distribution towards lower values (Fig. 10b). These evolutions are explained since the LSCF/gas specific surface area impacts the excorporation (R2), deionization (R4) and desorption (R6) identified as the rate-determining steps at OCP. Indeed, it has been observed that all these reactions are at the origin of the skewed semicircle arising at low frequencies in the spectrum. Regarding the loss of ionic conductivity, the decrease of $D_{\text {chem }}$ induces a swelling of the contribution at intermediate frequency in the Gerischer type-element (Fig. 10c). This behavior is associated to the diffusion of the oxygen vacancies in LSCF co-limiting the electrode response [39]. This evolution is concomitant with a very slight increase of the apex frequency in the Bode plots (Fig. 10d). At OCP, it can be noticed that the impact of the specific surface area on $R_{p o l}$ (Fig. 10e) is higher with respect to the loss of ionic conductivity (Fig. 10f). Considering a decrease of $30 \%$ for both studied parameters, the polarization resistance is increased by $25 \%$ for the surface passivation, while an augmentation of only $12 \%$ was simulated for the loss of ionic conductivity. This result means that the co-limitation at OCP due to the reactions involved in the bulk path is higher than the resistance induced by the oxygen vacancies diffusion in LSCF.

Degradation under polarization-As expected, the same trends than the ones found at OCP have been observed for the evolutions of the impedance diagrams under dc currents. The degradation of the electrode polarization resistance due to the surface passivation in SOFC and SOEC modes is given in Fig. 11a, while the impact of the loss of ionic conductivity is shown Fig. 11b. It is found that the decrease of the specific surface area is more impacting when the electrode is operated in the electrolysis mode compared to the fuel cell mode (Fig. 11a). In other words, the surface passivation is more detrimental under anodic current. This result can be correlated with the higher contribution of the surface path under anodic polarization. In this condition, the two pathways become co-limited by decreasing the surface reaction belonging to the common path. 
Besides, it is worth reminding that the flux of the adsorbed oxygen ions, which have been identified as a rate-determining step for the surface path (cf. section 5.1), also depends on the LSCF/gas specific surface area. Therefore, the decrease of this flux due to the surface passivation prevents the activation of the surface path.

In contrast to the passivation, the electrode performances are more impacted by the decrease of $D_{\text {chem }}$ when it is operated under fuel cell mode (Fig. 11b). Indeed, as already mentioned, the bulk path is co-limited by the oxygen solid-state diffusion in the perovskite. Therefore, the decrease of the ionic conductivity due to the LSCF demixing is especially harmful when this reaction pathway is predominant.

It can be noticed in Fig. 11a and $11 \mathrm{~b}$ that the impact of the surface passivation on the electrode response seems to be higher than the one induced by the loss of ionic conductivity. This result would indicate that the contribution of the LSCF demixing on the loss of electrode performances is more related to the surface deactivation than to an evolution of the LSCF bulk properties. This suggestion is in good agreement with the statement made by some authors who have observed an electrode recovery thanks to an LSCF surface etching treatment after aging $[24,83]$. Therefore, the present modeling result would strengthen the claim that 'the degradation is most likely due to the emergence of surface inhibited species on LSCF electrode' [24].

Moreover, the sum of the degradation due to the surface passivation and the loss of ionic conductivity, is higher in electrolysis mode (Fig. 11). In other words, the impact of LSCF degradation is higher under anodic polarization, addressing a double penalty for this operating mode since the Sr segregation seems to be also promoted in this operating mode $[20,84,85$, 86]. Finally, it is worth mentioning that, even for the considered lower bound for the LSCF decomposition, the impact on the electrode performance is not negligible meaning that the demixing remains an important issue for the SOCs durability.

\section{Conclusions}

An elementary kinetic model was developed to predict the electrochemical response of the LSCF and LSCF-CGO porous electrodes. The model describes the mass and charge fluxes in the porosity and in the bulk of the solid phases along with the transport of adsorbed species at the surface of the electrode particles. In this frame, the presence of oxygen ad-ions has been assumed onto the LSCF particles leading to take into account a surface electrostatic potential. 
For impedance simulations, the mass and charge conservations are solved in the time domain by taking into account the kinetic rates and the transient terms for all the considered species.

The model was validated thanks to experiments performed on symmetrical cells using a threeelectrode setup. The missing parameters corresponding to the kinetic constants and surface diffusivities have been determined by fitting the polarization curves obtained at three temperatures $\left(650^{\circ} \mathrm{C}, 700^{\circ} \mathrm{C}\right.$ and $\left.750^{\circ} \mathrm{C}\right)$. It is worth mentioning that it was possible to identify a single solution of the fitted parameters for both electrodes thanks to the dissymmetry of the curves, especially at low temperature. Besides, the two sets of values have been found to be consistent between the two types of studied electrodes. After the calibration, it has been shown that, without additional fitting, the model is able to simulate accurately the experimental EIS diagrams at OCP and under polarization for all the investigated temperatures. Moreover, the evolution of the electrode polarization resistance with the oxygen partial pressure is also well captured by the model. Indeed, a very good agreement has been found between the experimental and simulated reaction orders for both electrodes. Nevertheless, it can be mentioned that a systematic frequency lag was obtained between the measured and simulated spectra. For this reason, further investigations are still required to elucidate the origin of this discrepancy.

Once validated, the model has been used to analyze deeply the LSCF and LSCF-CGO reaction mechanisms. It has been confirmed that, at low and intermediate temperatures $\left(\leq 700^{\circ} \mathrm{C}\right)$, the LSCF exhibits a net change of reaction pathway from the bulk to the surface path at low anodic polarization. However, this transition has been found to be smoother and delayed at higher anodic current with increasing the temperature $\left(\geq 800^{\circ} \mathrm{C}\right)$, probably due to the small overpotential value. On the contrary, the LSCF-CGO electrode remains fully controlled by the surface path except at low temperature and high cathodic polarization. Besides, the dependency of the reaction mechanism with the oxygen partial pressure has been also studied at $700^{\circ} \mathrm{C}$. For both electrodes, the decrease of the electrode polarization with $P_{\mathrm{O}_{2}}$ is associated to a higher contribution of the surface path in the reaction mechanism. This behavior has been ascribed to the combined evolution of oxygen at the surface and in the bulk of LSCF as a function of $P_{\mathrm{O}_{2}}$. In addition, the rate-determining steps at OCP have been identified for the LSCF depending on the oxygen partial pressure. When the reaction mechanism is mainly controlled by the bulk path at low $P_{O_{2}}$, the global kinetic rate is co-limited by the oxygen excorporation, the surface ionization and the desorption. For a higher contribution of the surface path at higher $P_{O_{2}}$, the 
charge transfer at TPBls and the surface diffusion of oxygen ad-ions become more and more co-limiting while the ionization and desorption remain two rate-determining steps.

Finally, the impact of the perovskite decomposition on the LSCF electrode response has been studied with the model at OCP and under anodic and cathodic dc currents. The surface passivation and the loss of ionic conductivity have been simulated by decreasing the specific surface area and the chemical diffusivity, respectively. At OCP, the impact of the demixing on the evolution of the impedance spectra have been discussed. It has been shown that the passivation affects the contribution at low frequency in the Gerisher-type element while the loss of ionic conductivity enlarges the contribution at intermediate frequency.

It has been stated that the surface passivation is more affecting the electrode response when the performances are evaluated under electrolysis mode. On the contrary, the electrode polarization resistance is more sensitive to the decrease of ionic conductivity when the response is evaluated in fuel cell mode. Finally, whatever the conditions, it appears that the surface passivation would be more impacting than the decrease of the ionic conductivity. Moreover, the sum of the degradation induced by the two phenomena is higher when the electrode response is computed in anodic polarization. Therefore, the LSCF decomposition would be more detrimental for the electrode performances in electrolysis mode.

\section{Acknowledgements}

This project has received funding from the Fuel Cells and Hydrogen 2 Joint Undertaking (JU) under grant agreement $n^{\circ} 825027$ (AD ASTRA project) and $n^{\circ} 874577$ (NewSOC project). The JU receives support from the European Union's Horizon 2020 research and innovation program and Denmark, France, Italy, Spain, Poland, Netherlands, Greece, Finland, Estonia, Germany, United Kingdom, Switzerland. The work has also been partially supported by the French National Agency (ANR) (ECOREVE project). 


\section{List of Symbols}

\section{Roman Symbols:}

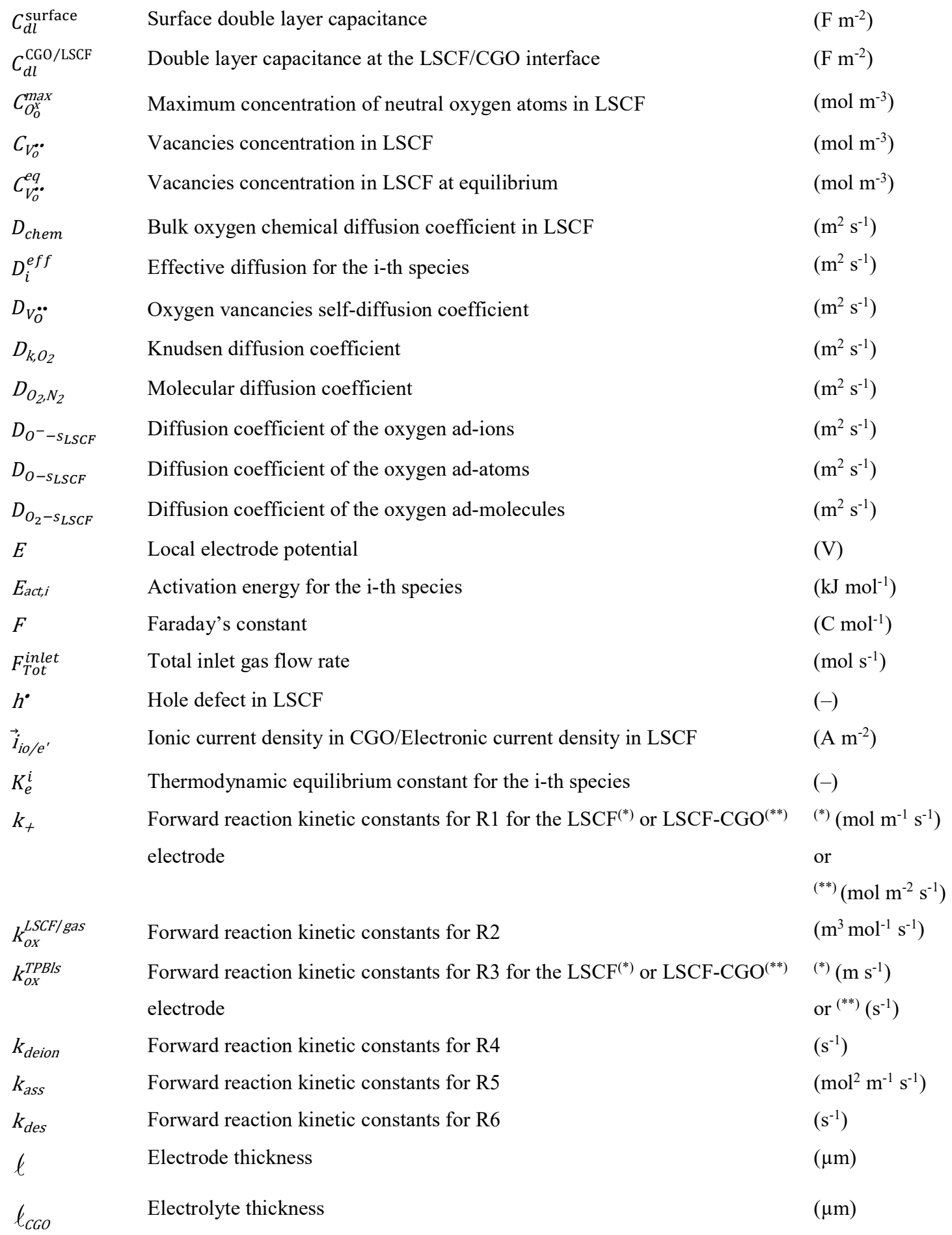




\begin{tabular}{|c|c|c|}
\hline$M_{i}$ & Molar mass for the i-th species & $\left(\mathrm{g} \mathrm{mol}^{-1}\right)$ \\
\hline$m$ & Reaction order & $(-)$ \\
\hline$\vec{N}_{i}$ & Molar flux of the i-th species & $\left(\mathrm{mol} \cdot \mathrm{m}^{-2} \cdot \mathrm{s}^{-1}\right)$ \\
\hline$O_{o}^{X}(L S C F)$ & Oxygen atom in the LSCF lattice & $(-)$ \\
\hline$O_{o}^{X}(C G O)$ & Oxygen atom in the CGO lattice & $(-)$ \\
\hline$O^{-}-S_{L S C F}$ & Oxygen ad-ion on LSCF surface & $(-)$ \\
\hline$O-S_{L S C F}$ & Oxygen ad-atom on LSCF surface & $(-)$ \\
\hline $\mathrm{O}_{2}-S_{L S C F}$ & Oxygen ad-molecule on LSCF surface & $(-)$ \\
\hline $\mathrm{O}_{2}$ & Gaseous oxygen molecule & $(-)$ \\
\hline$P_{\mathrm{O}_{2}}$ & Oxygen partial pressure & $(\mathrm{atm})$ \\
\hline$P_{t}$ & Total pressure & $(\mathrm{atm})$ \\
\hline $\bar{r}_{\text {pores }}$ & Mean pore radius & $(\mathrm{m})$ \\
\hline$R$ & Universal gas constant & $\left(\mathrm{J} \mathrm{mol}^{-1} \mathrm{~K}^{-1}\right)$ \\
\hline$R_{s}$ & Serial resistance & $\Omega \mathrm{cm}^{2}$ \\
\hline$R_{p}$ & Polarization resistance & $\Omega \mathrm{cm}^{2}$ \\
\hline$S_{L S C F}$ & Adsorption site on LSCF surface & $(-)$ \\
\hline$C C G O / L S C F$ & Specific surface area between CGO and LSCF for the $\mathrm{LSCF}^{(*)}$ or LSCF- & ${ }^{(*)}(-)$ \\
\hline & $\mathrm{CGO}^{(* *)}$ electrode & or $^{(* *)}\left(\mathrm{m}^{-1}\right)$ \\
\hline$S_{p}^{L S C F / g a s}$ & Specific surface area between LSCF and gas phase & $\left(\mathrm{m}^{-1}\right)$ \\
\hline$S_{e l}$ & Electrode surface & $\left(\mathrm{cm}^{2}\right)$ \\
\hline$T$ & Absolute temperature & $(\mathrm{K})$ \\
\hline$V_{i}$ & Fuller's volume for the i-th species & $(-)$ \\
\hline$V_{o}^{\cdot \bullet}(L S C F)$ & Oxygen vacancy in the LSCF lattice & $(-)$ \\
\hline$V_{o}^{\cdot \bullet}(C G O)$ & Oxygen vacancy in the CGO lattice & $(-)$ \\
\hline$y_{(i)}$ & Molar fraction of species i-th species & $(-)$ \\
\hline
\end{tabular}

\section{Greek Symbols:}

$\begin{array}{lll}\alpha_{R i}^{o X / \text { red }} & \text { Charge transfer coefficient for oxidation or reduction for the reaction Ri } & (-) \\ \Gamma & \text { Surface density of available sites on LSCF } & \left(\mathrm{mol} \mathrm{m}^{-2}\right) \\ \varepsilon X & \text { Phase volume fraction for the phase X } & (-) \\ \eta & \text { Overpotential } & (\mathrm{V}) \\ \theta_{O^{-}-s_{L S C F}} & \text { Coverage of oxygen ions on LSCF } & (-) \\ \theta_{O-s_{L S C F}} & \text { Coverage of oxygen atoms on LSCF } & (-) \\ \theta_{O_{2-} s_{L S C F}} & \text { Coverage of oxygen molecules on LSCF } & (-) \\ \theta_{S_{L S C F}} & \text { Free sites on the LSCF surface } & (-) \\ \theta_{O^{-}}^{e q} & \text { Coverage rate of oxygen ions on LSCF at equilibrium } & (-) \\ \theta_{O-s_{L S C F}}^{e q} & \text { Coverage rate of oxygen atoms on LSCF at equilibrium } & (-)\end{array}$




$\begin{array}{lll}\theta_{O_{2}-s_{L S C F}}^{e q} & \text { Coverage rate of oxygen molecules on LSCF at equilibrium } & (-) \\ \theta_{S_{L S C F}}^{e q} & \text { Free site on LSCF at equilibrium } & (-) \\ v_{(i)} & \begin{array}{l}\text { Kinetic rate of chemical/electrochemical reaction (i) in the electrode }{ }^{(*)} \text { or } \\ \text { at the electrolyte interface }\end{array} & { }^{(* *)}\left(\mathrm{mol} \mathrm{m}^{-3} \mathrm{~s}^{-1}\right) \\ \tilde{\mu}_{i} & \text { Electrochemical potential } & \text { or }^{(*)}\left(\mathrm{mol} \mathrm{m}^{-2} \mathrm{~s}^{-1}\right) \\ \xi_{T P B I s} & \text { Density of triple phase boundary lengths for the } \mathrm{LSCF}^{(*)} \text { or } \mathrm{LSCF}_{\mathrm{CGO}} \mathrm{CGO}^{(* *)} & \left(\mathrm{J} \mathrm{mol}^{-1}\right) \\ \sigma_{h_{L S C F}^{*}} & \text { electrode } & \left.\mathrm{m}^{-1}\right) \\ \sigma_{i o, C G O} & \text { Electronic conductivity of LSCF } & \mathrm{or}^{(* *)}\left(\mathrm{m}^{-2}\right) \\ \sigma_{i}^{e f f} & \text { Ionic conductivity of CGO } & \left(\mathrm{S} \mathrm{m}^{-1}\right) \\ \varphi_{i} & \text { Effective conductivity for th i-th species } & \left(\mathrm{S} \mathrm{m}^{-1}\right) \\ \chi & \text { Potential } & \left(\mathrm{S} \mathrm{m}^{-1}\right) \\ \tau_{X} & \text { Surface electrostatic potential } & (\mathrm{V}) \\ & \text { Tortuosity factor for the phase X } & (\mathrm{V})\end{array}$

\section{List of Abbreviations}

$\begin{array}{ll}\text { AFC } & \text { Alkaline Fuel Cell } \\ \text { CE } & \text { Counter Electrode } \\ \text { CGO } & \text { Ceria doped Gadolinium Oxide } \\ \text { DFT } & \text { Density Functional Theory } \\ \text { EIS } & \text { Electrochemical Impedance Spectroscopy } \\ \text { FIB-SEM } & \text { Focused Ion Beam-Scanning Electron Microscopy } \\ \text { LSCF } & \text { Lanthanum Strontium Cobalt Ferrite } \\ \text { MIEC } & \text { Mixed Ionic and Electronic Conductor } \\ \text { OCP } & \text { Open Circuit Potential } \\ \text { PEM } & \text { Proton-Exchange Membrane } \\ \text { RE } & \text { Reference Electrode } \\ \text { SOC } & \text { Solid Oxide Cells } \\ \text { SOFC } & \text { Solid Oxide Fuel Cell } \\ \text { SOEC } & \text { Solid Oxide Electrolysis Cell } \\ \text { TPBls } & \text { Triple Phase Boundary lengths } \\ \text { WE } & \text { Working Electrode } \\ \text { YSZ } & \text { Yttria Stabilized Zirconia }\end{array}$




\section{References}

[1] B. Zhu, Advantages of intermediate temperature solid oxide fuel cells for tractionary applications, J. Power Sources. 93 (2001) 82-86. https://doi.org/10.1016/S03787753(00)00564-4.

[2] K. Eguchi, H. Kojo, T. Takeguchi, R. Kikuchi, K. Sasaki, Fuel flexibility in power generation by solid oxide fuel cells, Solid State Ion. 152-153 (2002) 411-416. https://doi.org/10.1016/S0167-2738(02)00351-X.

[3] C. Graves, S.D. Ebbesen, M. Mogensen, K.S. Lackner, Sustainable hydrocarbon fuels by recycling $\mathrm{CO} 2$ and $\mathrm{H} 2 \mathrm{O}$ with renewable or nuclear energy, Renew. Sustain. Energy Rev. 15 (2011) 1-23. https://doi.org/10.1016/j.rser.2010.07.014.

[4] F. Monaco, M. Hubert, J. Vulliet, D. Montinaro, J.P. Ouweltjes, P. Cloetens, P. Piccardo, F. Lefebvre-Joud, J. Laurencin, Impact of Microstructure and Polarization on the Degradation of Ni-YSZ Electrode: An Experimental and Modeling Approach, ECS Trans. 91 (2019) 653. https://doi.org/10.1149/09101.0653ecst.

[5] M. Hubert, J. Laurencin, P. Cloetens, B. Morel, D. Montinaro, F. Lefebvre-Joud, Impact of Nickel agglomeration on Solid Oxide Cell operated in fuel cell and electrolysis modes, J. Power Sources. 397 (2018) 240-251. https://doi.org/10.1016/j.jpowsour.2018.06.097.

[6] S. Uhlenbruck, T. Moskalewicz, N. Jordan, H.-J. Penkalla, H.P. Buchkremer, Element interdiffusion at electrolyte-cathode interfaces in ceramic high-temperature fuel cells, Solid State Ion. 180 (2009) 418-423. https://doi.org/10.1016/j.ssi.2009.01.014.

[7] H. Yokokawa, H. Tu, B. Iwanschitz, A. Mai, Fundamental mechanisms limiting solid oxide fuel cell durability, J. Power Sources. 182 (2008) 400-412. https://doi.org/10.1016/j.jpowsour.2008.02.016.

[8] C. Xia, M. Liu, Novel Cathodes for Low-Temperature Solid Oxide Fuel Cells, Adv. Mater. 14 (2002) 521-523. https://doi.org/10.1002/15214095(20020404)14:7<521::AID-ADMA521>3.0.CO;2-C.

[9] C. Sun, R. Hui, J. Roller, Cathode materials for solid oxide fuel cells: a review, J. Solid State Electrochem. 14 (2010) 1125-1144. https://doi.org/10.1007/s10008-009-0932-0.

[10] V. Dusastre, J.A. Kilner, Optimisation of composite cathodes for intermediate temperature SOFC applications, Solid State Ion. 126 (1999) 163-174. https://doi.org/10.1016/S0167-2738(99)00108-3.

[11] Y. Leng, S.H. Chan, Q. Liu, Development of LSCF-GDC composite cathodes for lowtemperature solid oxide fuel cells with thin film GDC electrolyte, Int. J. Hydrog. Energy. 33 (2008) 3808-3817. https://doi.org/10.1016/j.ijhydene.2008.04.034.

[12] W.G. Wang, M. Mogensen, High-performance lanthanum-ferrite-based cathode for SOFC, Solid State Ion. 176 (2005) 457-462. https://doi.org/10.1016/j.ssi.2004.09.007.

[13] H.J. Hwang, J.-W. Moon, S. Lee, E.A. Lee, Electrochemical performance of LSCFbased composite cathodes for intermediate temperature SOFCs, J. Power Sources. 145 (2005) 243-248. https://doi.org/10.1016/j.jpowsour.2005.02.063.

[14] M.D. Anderson, J.W. Stevenson, S.P. Simner, Reactivity of lanthanide ferrite SOFC cathodes with YSZ electrolyte, J. Power Sources. 129 (2004) 188-192. https://doi.org/10.1016/j.jpowsour.2003.11.039.

[15] J. Villanova, S. Schlabach, A. Brisse, A. Léon, X-ray fluorescence nano-imaging of long-term operated solid oxide electrolysis cells, J. Power Sources. 421 (2019) 100-108. https://doi.org/10.1016/j.jpowsour.2019.02.084. 
[16] D. The, S. Grieshammer, M. Schroeder, M. Martin, M. Al Daroukh, F. Tietz, J. Schefold, A. Brisse, Microstructural comparison of solid oxide electrolyser cells operated for $6100 \mathrm{~h}$ and 9000 h, J. Power Sources. 275 (2015) 901-911. https://doi.org/10.1016/j.jpowsour.2014.10.188.

[17] R. Kiebach, W.-W. Zhang, W. Zhang, M. Chen, K. Norrman, H.-J. Wang, J.R. Bowen, R. Barfod, P.V. Hendriksen, Stability of La0.6Sr0.4Co0.2Fe0.8O3/Ce0.9Gd0.1O2 cathodes during sintering and solid oxide fuel cell operation, J. Power Sources. 283 (2015) 151-161. https://doi.org/10.1016/j.jpowsour.2015.02.064.

[18] F. Tietz, V.A.C. Haanappel, A. Mai, J. Mertens, D. Stöver, Performance of LSCF cathodes in cell tests, J. Power Sources. 156 (2006) 20-22. https://doi.org/10.1016/j.jpowsour.2005.08.015.

[19] C.E. Frey, Q. Fang, D. Sebold, L. Blum, N.H. Menzler, A Detailed Post Mortem Analysis of Solid Oxide Electrolyzer Cells after Long-Term Stack Operation, J. Electrochem. Soc. 165 (2018) F357-F364. https://doi.org/10.1149/2.0961805jes.

[20] J. Laurencin, M. Hubert, D.F. Sanchez, S. Pylypko, M. Morales, A. Morata, B. Morel, D. Montinaro, F. Lefebvre-Joud, E. Siebert, Degradation mechanism of $\mathrm{La} 0.6 \mathrm{Sr} 0.4 \mathrm{Co} 0.2 \mathrm{Fe} 0.8 \mathrm{O} 3-\delta / \mathrm{Gd} 0.1 \mathrm{Ce} 0.9 \mathrm{O} 2-\delta$ composite electrode operated under solid oxide electrolysis and fuel cell conditions, Electrochimica Acta. 241 (2017) 459-476. https://doi.org/10.1016/j.electacta.2017.05.011.

[21] H. Ding, A. V. Virkar, M. Liu, F. Liu, Suppression of Sr surface segregation in La 1-x Sr x Co $1-y$ Fe y O 3- $\delta$ : a first principles study, Phys. Chem. Chem. Phys. 15 (2013) 489-496. https://doi.org/10.1039/C2CP43148C.

[22] D. Kim, J.W. Park, B.-H. Yun, J.H. Park, K.T. Lee, Correlation of Time-Dependent Oxygen Surface Exchange Kinetics with Surface Chemistry of La0.6Sr0.4Co0.2Fe0.8O3- $\delta$ Catalysts, ACS Appl. Mater. Interfaces. 11 (2019) 3178631792. https://doi.org/10.1021/acsami.9b06569.

[23] H. Wang, S.A. Barnett, Degradation Mechanisms of Porous La0.6Sr0.4Co0.2Fe0.8O3- $\delta$ Solid Oxide Fuel Cell Cathodes, J. Electrochem. Soc. 165 (2018) F564-F570. https://doi.org/10.1149/2.1211807jes.

[24] Z. Pan, Q. Liu, L. Zhang, X. Zhang, S.H. Chan, Effect of Sr Surface Segregation of $\mathrm{La} 0.6 \mathrm{Sr} 0.4 \mathrm{Co} 0.2 \mathrm{Fe} 0.8 \mathrm{O} 3-\delta$ Electrode on Its Electrochemical Performance in SOC, J. Electrochem. Soc. 162 (2015) F1316-F1323. https://doi.org/10.1149/2.0371512jes.

[25] E. Lay-Grindler, J. Laurencin, G. Delette, J. Aicart, M. Petitjean, L. Dessemond, Micro modelling of solid oxide electrolysis cell: From performance to durability, Int. J. Hydrog. Energy. 38 (2013) 6917-6929. https://doi.org/10.1016/j.ijhydene.2013.03.162.

[26] S.B. Adler, J.A. Lane, B.C.H. Steele, Electrode Kinetics of Porous Mixed-Conducting Oxygen Electrodes, J. Electrochem. Soc. 143 (1996) 3554-3564. https://doi.org/10.1149/1.1837252.

[27] M. Prestat, J.-F. Koenig, L.J. Gauckler, Oxygen reduction at thin dense

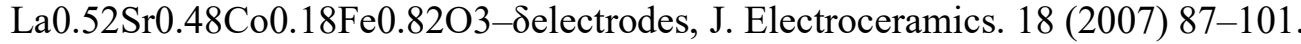
https://doi.org/10.1007/s10832-007-9012-y.

[28] F.S. Baumann, J. Fleig, G. Cristiani, B. Stuhlhofer, H.-U. Habermeier, J. Maier, Quantitative Comparison of Mixed Conducting SOFC Cathode Materials by Means of Thin Film Model Electrodes, J. Electrochem. Soc. 154 (2007) B931. https://doi.org/10.1149/1.2752974.

[29] N. Grunbaum, L. Dessemond, J. Fouletier, F. Prado, L. Mogni, A. Caneiro, Rate limiting steps of the porous $\mathrm{La} 0.6 \mathrm{Sr} 0.4 \mathrm{Co} 0.8 \mathrm{Fe} 0.2 \mathrm{O} 3-\delta$ electrode material, Solid State Ion. 180 (2009) 1448-1452. https://doi.org/10.1016/j.ssi.2009.09.005.

[30] J. Laurencin, M. Hubert, K. Couturier, T.L. Bihan, P. Cloetens, F. Lefebvre-Joud, E. Siebert, Reactive Mechanisms of LSCF Single-Phase and LSCF-CGO Composite 
Electrodes Operated in Anodic and Cathodic Polarisations, Electrochimica Acta. 174 (2015) 1299-1316. https://doi.org/10.1016/j.electacta.2015.06.080.

[31] F. Monaco, V. Tezyk, E. Siebert, S. Pylypko, B. Morel, J. Vulliet, T. Le Bihan, F. Lefebvre-Joud, J. Laurencin, Experimental validation of a $\mathrm{La} 0.6 \mathrm{Sr} 0.4 \mathrm{Co} 0.2 \mathrm{Fe} 0.8 \mathrm{O} 3-\delta$ electrode model operated in electrolysis mode: Understanding the reaction pathway under anodic polarization, Solid State Ion. 319 (2018) 234-246. https://doi.org/10.1016/j.ssi.2018.02.012.

[32] E. Effori, H. Moussaoui, F. Monaco, R.K. Sharma, J. Debayle, Y. Gavet, G. Delette, G.S. Larbi, E. Siebert, J. Vulliet, L. Dessemond, J. Laurencin, Reaction Mechanism and Impact of Microstructure on Performances for the LSCF-CGO Composite Electrode in Solid Oxide Cells, Fuel Cells. 19 (2019) 429-444. https://doi.org/10.1002/fuce.201800185.

[33] M. Liu, Z. Wu, Significance of interfaces in solid-state cells with porous electrodes of mixed ionic-electronic conductors, Solid State Ion. 107 (1998) 105-110. https://doi.org/10.1016/S0167-2738(97)00528-6.

[34] F.S. Baumann, J. Fleig, H.-U. Habermeier, J. Maier, Impedance spectroscopic study on well-defined ( $\mathrm{La}, \mathrm{Sr})(\mathrm{Co}, \mathrm{Fe}) \mathrm{O} 3-\delta$ model electrodes, Solid State Ion. 177 (2006) 10711081. https://doi.org/10.1016/j.ssi.2006.02.045.

[35] N.J. Simrick, A. Bieberle-Hütter, T.M. Ryll, J.A. Kilner, A. Atkinson, J.L.M. Rupp, An investigation of the oxygen reduction reaction mechanism of $\mathrm{La} 0.6 \mathrm{Sr} 0.4 \mathrm{Co} 0.2 \mathrm{Fe} 0.8 \mathrm{O} 3$ using patterned thin films, Solid State Ion. 206 (2012) 7-16. https://doi.org/10.1016/j.ssi.2011.10.029.

[36] Özden Çelikbilek, D. Jauffrès, E. Siebert, L. Dessemond, M. Burriel, C.L. Martin, E. Djurado, Rational design of hierarchically nanostructured electrodes for solid oxide fuel cells, J. Power Sources. 333 (2016) 72-82. https://doi.org/10.1016/j.jpowsour.2016.09.156.

[37] T. Carraro, J. Joos, B. Rüger, A. Weber, E. Ivers-Tiffée, 3D finite element model for reconstructed mixed-conducting cathodes: I. Performance quantification, Electrochimica Acta. 77 (2012) 315-323. https://doi.org/10.1016/j.electacta.2012.04.109.

[38] J. Deseure, Y. Bultel, L. Dessemond, E. Siebert, Modelling of dc and ac responses of a planar mixed conducting oxygen electrode, Solid State Ion. 176 (2005) 235-244. https://doi.org/10.1016/j.ssi.2004.07.018.

[39] M. Hubert, J. Laurencin, P. Cloetens, J.C. da Silva, F. Lefebvre-Joud, P. Bleuet, A. Nakajo, E. Siebert, Role of microstructure on electrode operating mechanisms for mixed ionic electronic conductors: From synchrotron-based 3D reconstruction to electrochemical modeling, Solid State Ion. 294 (2016) 90-107. https://doi.org/10.1016/j.ssi.2016.07.001.

[40] L. Ma, P. Priya, N.R. Aluru, A Multiscale Model for Electrochemical Reactions in LSCF Based Solid Oxide Cells, J. Electrochem. Soc. 165 (2018) F1232. https://doi.org/10.1149/2.0921814jes.

[41] B.A. Boukamp, H.J.M. Bouwmeester, Interpretation of the Gerischer impedance in solid state ionics, Solid State Ion. 157 (2003) 29-33. https://doi.org/10.1016/S01672738(02)00185-6.

[42] J. Nielsen, T. Jacobsen, M. Wandel, Impedance of porous IT-SOFC LSCF:CGO composite cathodes, Electrochimica Acta. 56 (2011) 7963-7974. https://doi.org/10.1016/j.electacta.2011.05.042.

[43] J.E. Mortensen, M. Søgaard, T. Jacobsen, Analytical, 1-Dimensional Impedance Model of a Composite Solid Oxide Fuel Cell Cathode, J. Electrochem. Soc. 161 (2014) F161F175. https://doi.org/10.1149/2.077401jes. 
[44] Z. Wang, R. Peng, W. Zhang, X. Wu, C. Xia, Y. Lu, Oxygen reduction and transport on the La 1-x Sr x Co 1-y Fe y O 3- $\delta$ cathode in solid oxide fuel cells: a first-principles study, J. Mater. Chem. A. 1 (2013) 12932-12940. https://doi.org/10.1039/C3TA11554B.

[45] J. Fleig, On the current-voltage characteristics of charge transfer reactions at mixed conducting electrodes on solid electrolytes, Phys. Chem. Chem. Phys. 7 (2005) 20272037. https://doi.org/10.1039/B501086A.

[46] J. Fleig, R. Merkle, J. Maier, The p (O 2 ) dependence of oxygen surface coverage and exchange current density of mixed conducting oxide electrodes: model considerations, Phys. Chem. Chem. Phys. 9 (2007) 2713-2723. https://doi.org/10.1039/B618765J.

[47] M. Gong, R.S. Gemmen, X. Liu, Modeling of oxygen reduction mechanism for 3PB and 2PB pathways at solid oxide fuel cell cathode from multi-step charge transfer, J. Power Sources. 201 (2012) 204-218. https://doi.org/10.1016/j.jpowsour.2011.11.002.

[48] V. Yurkiv, R. Costa, Z. Ilhan, A. Ansar, W.G. Bessler, Impedance of the Surface Double Layer of LSCF/CGO Composite Cathodes: An Elementary Kinetic Model, J. Electrochem. Soc. 161 (2014) F480-F492. https://doi.org/10.1149/2.070404jes.

[49] A. Donazzi, G. Cordaro, A. Baricci, Z.-B. Ding, M. Maestri, A detailed kinetic model for the reduction of oxygen on LSCF-GDC composite cathodes, Electrochimica Acta. 335 (2020) 135620. https://doi.org/10.1016/j.electacta.2020.135620.

[50] S.P. Jiang, Placement of Reference Electrode, Electrolyte Thickness and ThreeElectrode Cell Configuration in Solid Oxide Fuel Cells: A Brief Review and Update on Experimental Approach, J. Electrochem. Soc. 164 (2017) F834. https://doi.org/10.1149/2.1331707jes.

[51] X. Jin, K. Huang, Precautions of Using Three-Electrode Configuration to Measure Electrode Overpotential in Solid Oxide Electrochemical Cells: Insights from Finite Element Modeling, J. Electrochem. Soc. 167 (2020) 124501. https://doi.org/10.1149/1945-7111/aba876.

[52] J. Rutman, I. Riess, Placement of reference electrode in solid state electrolyte cells, Solid State Ion. 179 (2008) 913-918. https://doi.org/10.1016/j.ssi.2008.01.071.

[53] J. Villanova, J. Laurencin, P. Cloetens, P. Bleuet, G. Delette, H. Suhonen, F. UsseglioViretta, 3D phase mapping of solid oxide fuel cell YSZ/Ni cermet at the nanoscale by holographic X-ray nanotomography, J. Power Sources. 243 (2013) 841-849. https://doi.org/10.1016/j.jpowsour.2013.06.069.

[54] F. Usseglio-Viretta, J. Laurencin, G. Delette, J. Villanova, P. Cloetens, D. Leguillon, Quantitative microstructure characterization of a Ni-YSZ bi-layer coupled with simulated electrode polarisation, J. Power Sources. 256 (2014) 394-403. https://doi.org/10.1016/j.jpowsour.2014.01.094.

[55] H. Moussaoui, J. Laurencin, Y. Gavet, G. Delette, M. Hubert, P. Cloetens, T. Le Bihan, J. Debayle, Stochastic geometrical modeling of solid oxide cells electrodes validated on 3D reconstructions, Comput. Mater. Sci. 143 (2018) 262-276. https://doi.org/10.1016/j.commatsci.2017.11.015.

[56] L. Holzer, D. Wiedenmann, B. Münch, L. Keller, M. Prestat, Ph. Gasser, I. Robertson, B. Grobéty, The influence of constrictivity on the effective transport properties of porous layers in electrolysis and fuel cells, J. Mater. Sci. 48 (2013) 2934-2952. https://doi.org/10.1007/s10853-012-6968-z.

[57] M. Che, A.J. Tench, Characterization and Reactivity of Molecular Oxygen Species on Oxide Surfaces, in: Adv. Catal., Elsevier, 1983: pp. 1-148. https://doi.org/10.1016/S0360-0564(08)60439-3.

[58] M. Che, A.J. Tench, Characterization and Reactivity of Mononuclear Oxygen Species on Oxide Surfaces, in: Adv. Catal., Elsevier, 1982: pp. 77-133. https://doi.org/10.1016/S0360-0564(08)60453-8. 
[59] J.E. ten Elshof, M.H.R. Lankhorst, H.J.M. Bouwmeester, Chemical diffusion and oxygen exchange of La0.6Sr0.4Co0.6Fe0.4O3- $\delta$, Solid State Ion. 99 (1997) 15-22. https://doi.org/10.1016/S0167-2738(97)00263-4.

[60] H.J.M. Bouwmeester, B.A. Boukamp, Oxygen transport in $\mathrm{La0.6Sr0.4Co1-yFeyO3- \delta ,} \mathrm{J}$ Solid State Elechtrochem. (2004) 599-605.

[61] B. Todd, J.B. Young, Thermodynamic and transport properties of gases for use in solid oxide fuel cell modelling, J. Power Sources. 110 (2002) 186-200. https://doi.org/10.1016/S0378-7753(02)00277-X.

[62] J.A. Lane, J.A. Kilner, Measuring oxygen diffusion and oxygen surface exchange by conductivity relaxation, Solid State Ion. 136-137 (2000) 997-1001. https://doi.org/10.1016/S0167-2738(00)00554-3.

[63] W.G. Bessler, Gas Concentration Impedance of Solid Oxide Fuel Cell Anodes: I. Stagnation Point Flow Geometry, J. Electrochem. Soc. 153 (2006) A1492. https://doi.org/10.1149/1.2205150.

[64] F. Monaco, E. Effori, M. Hubert, E. Siebert, G. Geneste, B. Morel, E. Djurado, D. Montinaro, J. Laurencin, Electrode Kinetics of Porous Ni-3YSZ Cermet Operated in Fuel Cell and Electrolysis Modes for Solid Oxide Cell Application, Summited Electrochem Acta. (2021).

[65] Y. Choi, M.C. Lin, M. Liu, Rational design of novel cathode materials in solid oxide fuel cells using first-principles simulations, J. Power Sources. 195 (2010) 1441-1445. https://doi.org/10.1016/j.jpowsour.2009.09.017.

[66] S. Hashimoto, Y. Fukuda, M. Kuhn, K. Sato, K. Yashiro, J. Mizusaki, Thermal and chemical lattice expansibility of $\mathrm{La} 0.6 \mathrm{Sr} 0.4 \mathrm{Co} 1-\mathrm{yFeyO}-\delta(\mathrm{y}=0.2,0.4,0.6$ and 0.8$)$, Solid State Ion. 186 (2011) 37-43. https://doi.org/10.1016/j.ssi.2011.01.014.

[67] R. Tanaka, W.S. Oliveira, A. Brandão, J.C.C. Abrantes, J.R. Frade, Grain boundary conductivity of heterogeneous ceria gadolinia, Electrochimica Acta. 85 (2012) 116-121. https://doi.org/10.1016/j.electacta.2012.08.009.

[68] K. Yashiro, I. Nakano, M. Kuhn, S. Hashimoto, K. Sato, J. Mizusaki, Electrical Conductivity and Oxygen Diffusivity of Perovskite-Type Solid Solution La0.6Sr0.4Co1yFeyO3- $\delta(y=0.2,0.4,0.5,0.6,0.8)$, ECS Trans. 35 (2011) 1899. https://doi.org/10.1149/1.3570179.

[69] S.B. Adler, Factors Governing Oxygen Reduction in Solid Oxide Fuel Cell Cathodes, Chem Rev. (2004) 4791-4844.

[70] A.V. Virkar, J. Chen, C.W. Tanner, J.-W. Kim, The role of electrode microstructure on activation and concentration polarizations in solid oxide fuel cells, Solid State Ion. 131 (2000) 189-198. https://doi.org/10.1016/S0167-2738(00)00633-0.

[71] A. He, Y. Kim, N. Shikazono, Numerical Simulation of LSCF-GDC Composite Cathodes with Various Microstructures, ECS Trans. 78 (2017) 2751-2763. https://doi.org/10.1149/07801.2751ecst.

[72] M.E. Brito, H. Morishita, J. Yamada, H. Nishino, H. Uchida, Further improvement in performances of $\mathrm{La} 0.6 \mathrm{Sr} 0.4 \mathrm{Co} 0.2 \mathrm{Fe} 0.8 \mathrm{O} 3-\delta$ - doped ceria composite oxygen electrodes with infiltrated doped ceria nanoparticles for reversible solid oxide cells, J. Power Sources. 427 (2019) 293-298. https://doi.org/10.1016/j.jpowsour.2019.04.066.

[73] F.J.A. Loureiro, D.A. Macedo, R.M. Nascimento, M.R. Cesário, J.P.F. Grilo, A.A. Yaremchenko, D.P. Fagg, Cathodic polarisation of composite LSCF-SDC IT-SOFC electrode synthesised by one-step microwave self-assisted combustion, J. Eur. Ceram. Soc. 39 (2019) 1846-1853. https://doi.org/10.1016/j.jeurceramsoc.2019.01.013.

[74] G. Hughes, J. Railsback, D. Butts, S.A. Barnett, Electrochemical Performance of Solid Oxide Cell Oxygen Electrodes Under Pressurization, ECS Trans. 68 (2015) 687. https://doi.org/10.1149/06801.0687ecst. 
[75] P. Costamagna, C. Sanna, A. Campodonico, E.M. Sala, R. Sažinas, P. Holtappels, Electrochemical Impedance Spectroscopy of Electrospun $\mathrm{La} 0.6 \mathrm{Sr} 0.4 \mathrm{Co} 0.2 \mathrm{Fe} 0.8 \mathrm{O} 3-\delta$ Nanorod Cathodes for Intermediate Temperature - Solid Oxide Fuel Cells, Fuel Cells. 19 (2019) 472-483. https://doi.org/10.1002/fuce.201800205.

[76] E. Perry Murray, M.J. Sever, S.A. Barnett, Electrochemical performance of (La,Sr)(Co,Fe)O3-(Ce,Gd)O3 composite cathodes, Solid State Ion. 148 (2002) 27-34. https://doi.org/10.1016/S0167-2738(02)00102-9.

[77] Özden Çelikbilek, E. Siebert, D. Jauffrès, C.L. Martin, E. Djurado, Influence of sintering temperature on morphology and electrochemical performance of LSCF/GDC composite films as efficient cathode for SOFC, Electrochimica Acta. 246 (2017) 12481258. https://doi.org/10.1016/j.electacta.2017.06.070.

[78] D. Marinha, L. Dessemond, J.S. Cronin, J.R. Wilson, S.A. Barnett, E. Djurado, Microstructural 3D Reconstruction and Performance Evaluation of LSCF Cathodes Obtained by Electrostatic Spray Deposition, Chem. Mater. 23 (2011) 5340-5348. https://doi.org/10.1021/cm2016998.

[79] M. Mosiałek, A. Michna, M. Dziubaniuk, E. Bielańska, A. Kežionis, T. Šalkus, E. Kazakevičius, B. Bożek, A. Krawczyk, J. Wyrwa, A.F. Orliukas, Composite cathode material LSCF-Ag for solid oxide fuel cells obtained in one step sintering procedure, Electrochimica Acta. 282 (2018) 427-436. https://doi.org/10.1016/j.electacta.2018.06.063.

[80] S.B. Adler, Mechanism and kinetics of oxygen reduction on porous La1 $-\mathrm{xSrxCoO}-\delta$ electrodes, Solid State Ion. 111 (1998) 125-134. https://doi.org/10.1016/S01672738(98)00179-9.

[81] H. Wang, K.J. Yakal-Kremski, T. Yeh, G.M. Rupp, A. Limbeck, J. Fleig, S.A. Barnett, Mechanisms of Performance Degradation of $(\mathrm{La}, \mathrm{Sr})(\mathrm{Co}, \mathrm{Fe}) \mathrm{O} 3-\delta$ Solid Oxide Fuel Cell Cathodes, J. Electrochem. Soc. 163 (2016) F581-F585. https://doi.org/10.1149/2.0031607jes.

[82] C. Endler-Schuck, J. Joos, C. Niedrig, A. Weber, E. Ivers-Tiffée, The chemical oxygen surface exchange and bulk diffusion coefficient determined by impedance spectroscopy of porous La0.58 Sr0.4Co0.2Fe0.8O3- $\delta$ (LSCF) cathodes, Solid State Ion. 269 (2015) 67-79. https://doi.org/10.1016/j.ssi.2014.11.018.

[83] M.Y. Lu, J.G. Railsback, H. Wang, Q. Liu, Y.A. Chart, S.-L. Zhang, S.A. Barnett, Stable high current density operation of $\mathrm{La} 0.6 \mathrm{Sr} 0.4 \mathrm{Co} 0.2 \mathrm{Fe} 0.8 \mathrm{O} 3-\delta$ oxygen electrodes, J. Mater. Chem. A. 7 (2019) 13531-13539. https://doi.org/10.1039/C9TA04020J.

[84] Y. Li, W. Zhang, Y. Zheng, J. Chen, B. Yu, Y. Chen, M. Liu, Controlling cation segregation in perovskite-based electrodes for high electro-catalytic activity and durability, Chem. Soc. Rev. 46 (2017) 6345-6378. https://doi.org/10.1039/C7CS00120G.

[85] A.-K. Huber, M. Falk, M. Rohnke, B. Luerßen, L. Gregoratti, M. Amati, J. Janek, In situ study of electrochemical activation and surface segregation of the SOFC electrode material La 0.75 Sr 0.25 Cr 0.5 Mn 0.5 O $3 \pm \delta$, Phys. Chem. Chem. Phys. 14 (2012) $751-$ 758. https://doi.org/10.1039/C1CP21743G.

[86] K. Chen, J. Hyodo, A. Dodd, N. Ai, T. Ishihara, L. Jian, S.P. Jiang, Chromium deposition and poisoning of $\mathrm{La} 0.8 \mathrm{Sr} 0.2 \mathrm{MnO} 3$ oxygen electrodes of solid oxide electrolysis cells, Faraday Discuss. 182 (2015) 457-476. https://doi.org/10.1039/C5FD00010F. 
Table I. Reactions and expressions of the kinetic rates (cf. list of symbols).

\begin{tabular}{|c|c|c|c|}
\hline \multicolumn{4}{|c|}{ Electrode } \\
\hline $\mathbf{N}^{\circ}$ & Reaction mechanisms & Kinetic rates & \\
\hline R1 & $\begin{aligned} & O_{o}^{x}(C G O)+V_{o}^{* \cdot}(L S C F) \stackrel{k_{+}}{\leftrightarrow} O_{o}^{x}(L S C F) \\
& k_{-} \\
&+V_{o}^{* \cdot}(C G O)\end{aligned}$ & $\begin{aligned} v_{(1)}=S_{p}^{C G O / L S C F}\left\{k_{+} \exp \left(\frac{2 \alpha_{(1)}^{o x} F E}{R T}\right)\left(\frac{C_{V_{o}^{*}}}{C_{O_{o}^{x}}^{\max }}\right)\right. & \\
& \left.-k_{-} \exp \left(\frac{-2 \alpha_{(1)}^{r e d} F E}{R T}\right)\left(\frac{C_{O_{o}^{x}}^{\max }-C_{V_{o}^{\prime \prime}}}{C_{O_{o}^{x}}^{\max }}\right)\right\}\end{aligned}$ & (1) \\
\hline $\mathrm{R} 2$ & $\begin{array}{c}O_{o}^{x}(L S C F)+1 h^{\bullet}+1 s_{L S C F} k_{o x}^{L S C F / g a s} \stackrel{\leftrightarrow}{L S C F / g a s} \\
k_{\text {red }}^{L \cdot *}(L S C F) \\
+O^{-}-s_{L S C F}\end{array}$ & $\begin{array}{l}v_{(2)} \\
=S_{p}^{L S C F / g a s}\left\{k_{o x}^{L S C F / g a s} \exp \left(\frac{\alpha_{(2)}^{o x} F \chi}{R T}\right)\left(\left(C_{O_{o}^{x}}^{\max }-C_{V_{o}^{*}}\right) \Gamma \theta_{S_{L S C F}}\right)\right. \\
\left.-k_{\text {red }}^{L S C F / g a s} \exp \left(\frac{-\alpha_{(2)}^{r e d} F \chi}{R T}\right)\left(\Gamma \theta_{O^{-}-s_{L S C F}} C_{V_{o}^{*}}\right)\right\}\end{array}$ & (2) \\
\hline R3 & $\begin{array}{c}O_{o}^{x}(C G O)+1 h^{\bullet}+1 s_{L S C F} \underset{o x}{\stackrel{k^{T P B l s}}{\leftrightarrow}} O^{-}-s_{L S C F} \\
k_{r e d}^{T P B l s} \\
+V_{o}^{* *}(C G O)\end{array}$ & $\begin{aligned} v_{(3)}=\xi_{T P B S}\left\{k_{o x}^{T P B l s}\right. & \exp \left(\frac{\alpha_{(3)}^{o x} F E}{R T}\right) \Gamma \theta_{s_{L S C F}} \\
& \left.-k_{r e d}^{T P B l s} \exp \left(\frac{-\alpha_{(3)}^{r e d} F E}{R T}\right) \Gamma \theta_{O^{-}-s_{L S C F}}\right\}\end{aligned}$ & (3) \\
\hline R4 & $O^{-}-s_{L S C F}+1 h^{\cdot} \underset{k_{\text {deion }}}{\leftrightarrow} O-s_{L S C F}$ & $\begin{aligned} v_{(4)}=S_{p}^{L S C F / g a s}\left\{k_{\text {deion }} \exp \left(\frac{\alpha_{(4)}^{o x} F \chi}{R T}\right)\left(\Gamma \theta_{0^{-}-s_{L S C F}}\right)\right. \\
\left.-k_{\text {ion }} \exp \left(\frac{-\alpha_{(4)}^{r e d} F \chi}{R T}\right)\left(\Gamma \theta_{O-s_{L S C F}}\right)\right\}\end{aligned}$ & (4) \\
\hline R5 & $2 O-s_{L S C F} \stackrel{k_{\text {ass }}^{\leftrightarrow}}{\leftrightarrow} O_{2}-s_{L S C F}+1 s_{L S C F}$ & $v_{(5)}=S_{p}^{L S C F / g a s}\left\{k_{a s s} \Gamma^{2} \theta_{O-s_{L S C F}}{ }^{2}-k_{\text {diss }} \Gamma^{2} \theta_{O_{2-} S_{L S C F}} \theta_{S_{L S C F}}\right\}$ & (5) \\
\hline R6 & $O_{2}-s_{L S C F} \underset{k_{\text {des }}}{\stackrel{k_{\text {ads }}}{\leftrightarrow} O_{2}(\text { gas })+1 s_{\text {LSCF }}}$ & $v_{(6)}=S_{p}^{L S C F / g a s}\left\{k_{d e s} \Gamma \theta_{O_{2}-s_{L S C F}}-k_{a d s} P_{O_{2}} \Gamma \theta_{S_{L S C F}}\right\}$ & (6) \\
\hline
\end{tabular}


Table II. Equations of charge and mass conservations associated to the current and the fluxes taken into account in the physically-based model together with the expression of the transport phenomena (given for the LSCF-CGO electrode).

\begin{tabular}{|c|c|c|c|}
\hline \multicolumn{4}{|c|}{ Electrode } \\
\hline \multicolumn{2}{|c|}{ Transport phenomena (fluxes) } & \multicolumn{2}{|l|}{ Conservation equations } \\
\hline $\overrightarrow{\mathrm{i}}_{\mathrm{io}}=-\frac{\varepsilon_{C G O}}{\tau_{C G O}} \sigma_{\mathrm{io}, \mathrm{CGO}} \times \vec{\nabla} \varphi_{\mathrm{CGO}}$ & (11) & $\vec{\nabla} \cdot \overrightarrow{\mathrm{i}}_{\mathrm{io}}=+2 \mathrm{~F}\left(v_{(1)}+v_{(3)}\right)-\mathrm{S}_{\mathrm{p}}^{\mathrm{CGO} / \mathrm{LSCF}} C_{d l}^{\mathrm{CGO} / \mathrm{LSCF}} \frac{\partial \mathrm{E}}{\partial \mathrm{t}}$ & (19) \\
\hline $\overrightarrow{\mathrm{N}}_{\mathrm{V}_{0} \cdot}=-\frac{\varepsilon_{L S C F}}{\tau_{L S C F}} \widetilde{D}_{\text {chem }} \times \vec{\nabla} \mathrm{C}_{\mathrm{V}_{0}}$ & (12) & 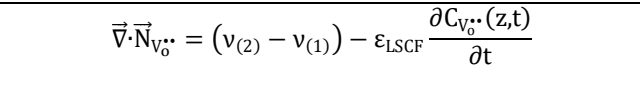 & $(20)$ \\
\hline 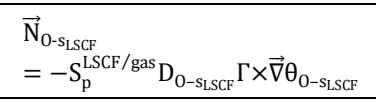 & (13) & $\vec{\nabla} \cdot \overrightarrow{\mathrm{N}}_{\mathrm{O}-\mathrm{s}_{\mathrm{LSCF}}}=\left(v_{(4)}-2 v_{(5)}\right)-\mathrm{S}_{\mathrm{p}}^{\mathrm{LSCF} / \mathrm{gas}} \Gamma \frac{\partial \theta_{0-\mathrm{s}_{\mathrm{LSCF}}}(\mathrm{z}, \mathrm{t})}{\partial \mathrm{t}}$ & (21) \\
\hline $\begin{array}{l}\overrightarrow{\mathrm{N}}_{\mathrm{O}^{-}-\mathrm{S}_{\mathrm{LSCF}}} \\
=-\mathrm{S}_{\mathrm{p}}^{\mathrm{SSCF} / \mathrm{gas}} \mathrm{D}_{\mathrm{O}^{-}-\mathrm{s}_{\mathrm{LSCF}}} \mathrm{\Gamma} \times \vec{\nabla} \theta_{\mathrm{O}^{-}-\mathrm{s}_{\mathrm{LSCF}}}\end{array}$ & (14) & $\vec{\nabla} \cdot \overrightarrow{\mathrm{N}}_{\mathrm{O}^{-}-\mathrm{S}_{\mathrm{LSCF}}}=\left(v_{(2)}+v_{(3)}-v_{(4)}\right)-\mathrm{S}_{\mathrm{p}}^{\mathrm{LSCF} / \mathrm{gas}} \Gamma \frac{\partial \theta_{0^{-}-\mathrm{S}_{\mathrm{LSCF}}}(\mathrm{z}, \mathrm{t})}{\partial \mathrm{t}}$ & $(22)$ \\
\hline $\begin{array}{l}\overrightarrow{\mathrm{N}}_{O_{2} \text { - } \mathrm{SLSCF}} \\
=-\mathrm{S}_{\mathrm{p}}^{\mathrm{LSCF} / \mathrm{gas}} \mathrm{D}_{O_{2}-\mathrm{S}_{\mathrm{LSCF}}} \Gamma \times \vec{\nabla} \theta_{O_{2}-\mathrm{S}_{\text {LSCF }}}\end{array}$ & (15) & $\vec{\nabla} \cdot \overrightarrow{\mathrm{N}}_{O_{2}-\mathrm{S}_{\mathrm{LSCF}}}=\left(v_{(5)}-v_{(6)}\right)-\mathrm{S}_{\mathrm{p}}^{\mathrm{LSCF} / \mathrm{gas}} \Gamma \frac{\partial \theta_{O_{2-} \mathrm{S}_{\mathrm{LSCF}}}(\mathrm{z}, \mathrm{t})}{\partial \mathrm{t}}$ & (23) \\
\hline $\begin{aligned} \vec{\nabla} \mathrm{y}_{\mathrm{O}_{2}}=-\frac{\mathrm{RT}}{\mathrm{P}_{\mathrm{t}}} \frac{\tau_{\text {pores }}}{\varepsilon_{\text {pores }}}\left(\frac{\vec{N}_{\mathrm{O}_{2}}}{\mathrm{D}_{\mathrm{k}, \mathrm{O}_{2}}}\right. & \\
& \left.+\frac{\vec{N}_{\mathrm{O}_{2}} \mathrm{y}_{\mathrm{N}_{2}}}{\mathrm{D}_{\mathrm{O}_{2}, \mathrm{~N}_{2}}}\right)\end{aligned}$ & (16) & $\vec{\nabla} \cdot \overrightarrow{\mathrm{N}}_{\mathrm{O}_{2}}=v_{(6)}-\frac{\varepsilon_{\text {pores }}}{\mathrm{RT}} \mathrm{P}_{\mathrm{t}} \frac{\partial \mathrm{y}_{\mathrm{O}_{2}}(\mathrm{z}, \mathrm{t})}{\partial \mathrm{t}}$ & (24) \\
\hline $\overrightarrow{\mathrm{i}}_{\mathrm{e}}=-\frac{\varepsilon_{L S C F}}{\tau_{L S C F}} \sigma_{\mathrm{h}_{\mathrm{LSCF}}} \times \vec{\nabla} \varphi_{\mathrm{LSCF}}$ & (17) & $\vec{\nabla} \cdot \overrightarrow{\mathrm{i}}_{\mathrm{e}}=-\mathrm{F}\left(v_{(2)}+v_{(3)}+v_{(4)}\right)+\mathrm{S}_{\mathrm{p}}^{\mathrm{CGO} / \mathrm{LSCF}} C_{d l}^{\mathrm{CGO} / \mathrm{LSCF}} \frac{\partial \mathrm{E}}{\partial \mathrm{t}}$ & (25) \\
\hline \multicolumn{4}{|c|}{ Electrolyte } \\
\hline $\overrightarrow{\mathrm{i}}_{\mathrm{i} O}=-\sigma_{\mathrm{i}, \mathrm{CGO}} \times \vec{\nabla} \varphi_{\mathrm{CGO}}$ & $(18)$ & $\vec{\nabla} \cdot \overrightarrow{\mathrm{i}}_{\mathrm{i} 0}=0$ & $(26)$ \\
\hline
\end{tabular}

Table III. Equations of the thermodynamic equilibrium constants (cf. List of symbols).

\begin{tabular}{|c|c|c|c|c|c|}
\hline $\mathbf{N}^{\circ}$ & \multicolumn{5}{|c|}{ Thermodynamic equilibrium constants } \\
\hline R1 & $K_{e}^{(1)}=\frac{C_{O_{o}^{x}}^{\max }-C_{V_{o}^{*}}^{e q}}{C_{V_{o}^{*}}^{e q}} \exp \left(\frac{-2 F E^{e q}}{R T}\right)$ & (32) & R4 & $K_{e}^{(4)}=\frac{\theta_{O-s_{L S C F}}^{e q}}{\theta_{O^{-}-s_{L S C F}}^{e q}} \exp \left(\frac{-F \chi^{e q}}{R T}\right)$ & (35) \\
\hline $\mathrm{R} 2$ & $K_{e}^{(2)}=\frac{\theta_{O^{-}-s_{L S C F}}^{e q} C_{V_{o}^{*}}^{e q}}{\theta_{S_{L S C F}^{e q}}^{e q}\left(C_{O_{o}^{x}}^{m a x}-C_{V_{o}^{*}}^{e q}\right)} \exp \left(\frac{-F \chi^{e q}}{R T}\right)$ & (33) & R5 & $K_{e}^{(5)}=\frac{\theta_{S_{L S C F}}^{e q}}{\left(\theta_{O_{2}-s_{L S C F}}^{e q} \theta_{O-S_{L S C F}}^{e q}\right)^{2}}$ & (36) \\
\hline R3 & $K_{e}^{(3)}=\frac{\theta_{O^{-}-s_{L S C F}}^{e q}}{\theta_{S_{L S C F}}^{e q}} \exp \left(\frac{-F E^{e q}}{R T}\right)$ & (34) & R6 & $K_{e}^{(6)}=\frac{\theta_{S_{L S C F} P_{O_{2}}^{e q}}^{e q}}{\theta_{O_{2}-s_{L S C F}}^{e q}}$ & (37) \\
\hline
\end{tabular}


Table IV. Model input parameters for the LSCF material given here at $700^{\circ} \mathrm{C}$ under $P_{O_{2}}=0.21$ atm.

\begin{tabular}{|c|c|c|}
\hline Parameter at $700^{\circ} \mathrm{C}, P_{O_{2}}=0.21 \mathrm{~atm}$ & Value & Unit \\
\hline Maximum oxygen concentration in the $\operatorname{LSCF}\left(C_{O_{0}^{x}}^{\max }\right)$ & 83108 & $\left(\mathrm{~mol} \cdot \mathrm{m}^{-3}\right)$ \\
\hline Equilibrium oxygen concentration in the $\operatorname{LSCF}\left(C_{O_{O}^{x}}^{e q}\right)$ & 82491 & $\left(\mathrm{~mol} \cdot \mathrm{m}^{-3}\right)$ \\
\hline Electronic conductivity of LSCF $\left(\sigma_{h_{\mathrm{hSCF}}}\right)$ & 33738 & $\left(\mathrm{~S} \cdot \mathrm{m}^{-1}\right)$ \\
\hline Ionic conductivity of CGO $\left(\sigma_{i o, C G O}\right)$ & 2.9 & $\left(\mathrm{~S} \cdot \mathrm{m}^{-1}\right)$ \\
\hline Density of available adsorption sites $(\Gamma)$ & $1 \cdot 10 \times 10^{-5}$ & $\left(\mathrm{~mol} \cdot \mathrm{m}^{-2}\right)$ \\
\hline LSCF chemical diffusivity $\left(D_{\text {chem }}\right)$ & $3.7 \times 10^{-10}$ & $\left(\mathrm{~m}^{2} \cdot \mathrm{s}^{-1}\right)$ \\
\hline LSCF/CGO double layer capacitance $\left(C_{d l}^{L S C F / C G O}\right)$ & 0.5 & $\left(\mathrm{~F} \cdot \mathrm{m}^{-2}\right)$ \\
\hline Surface double layer capacitance $\left(C_{d l}^{\text {surface }}\right)$ & 0.2 & $\left(\mathrm{~F} \cdot \mathrm{m}^{-2}\right)$ \\
\hline Knudsen diffusion coefficient $\left(\mathrm{D}_{\mathrm{k}, \mathrm{O}_{2}}\right)$ & 535 & $\left(\mathrm{~m}^{2} \cdot \mathrm{s}^{-1}\right)$ \\
\hline Molecular diffusion coefficient $\left(\mathrm{D}_{\mathrm{O}_{2}, \mathrm{~N}_{2}}\right)$ & $1.65 \times 10^{-4}$ & $\left(\mathrm{~m}^{2} \cdot \mathrm{s}^{-1}\right)$ \\
\hline Charge transfer coefficient $\left(\alpha^{o x}\right)$ & 0.5 & $(-)$ \\
\hline
\end{tabular}

Table V. Microstructural properties of the LSCF and LSCF-CGO electrodes computed on the FIB-SEM reconstructions (cf. List of symbols).

\begin{tabular}{|c|c|c|c|c|}
\hline & \multicolumn{2}{|c|}{ LSCF } & \multicolumn{2}{c|}{ LSCF-CGO } \\
\hline $\begin{array}{c}\text { Microstructural } \\
\text { properties }\end{array}$ & Values & Unit & Values & Unit \\
\hline$\varepsilon_{L S C F}$ & 48.7 & $(\%)$ & 30.2 & $(\%)$ \\
\hline$\varepsilon_{\text {pores }}$ & 51.3 & $(\%)$ & 43.5 & $(\%)$ \\
\hline$\varepsilon_{C G O}$ & - & - & 26.4 & $(\%)$ \\
\hline$S_{p}^{L S C F / G a s}$ & $3.59 \times 10^{6}$ & $\left(\mathrm{~m}^{-1}\right)$ & $2.20 \times 10^{6}$ & $\left(\mathrm{~m}^{-1}\right)$ \\
\hline$S_{p}^{L S C F / C G O}$ & $2.08 \times 10^{-2}$ & $(-)$ & $1.06 \times 10^{6}$ & $\left(\mathrm{~m}^{-1}\right)$ \\
\hline $\bar{r}_{\text {pores }}$ & $2.10 \times 10^{-7}$ & $(\mathrm{~m})$ & $1.70 \times 10^{-7}$ & $(\mathrm{~m})$ \\
\hline$\tau_{L S C F}$ & 2.84 & $(-)$ & 1.77 & $(-)$ \\
\hline$\tau_{\text {pores }}$ & 1.66 & $(-)$ & 1.55 & $(-)$ \\
\hline$\tau_{C G O}$ & - & - & 1.84 & $(-)$ \\
\hline$\xi_{T P B l s}$ & $5.57 \times 10^{5}$ & $\left(\mathrm{~m}^{-1}\right)$ & $9.06 \times 10^{12}$ & $\left(\mathrm{~m}^{-2}\right)$ \\
\hline
\end{tabular}


Table VI. Model parameters fitted on the i-V curves for the LSCF and LSCF-CGO electrode at $700^{\circ} \mathrm{C}$.

\begin{tabular}{|c|c|c|c|c|c|c|}
\hline Parameters $700^{\circ} \mathrm{C}$ & \multicolumn{3}{|c|}{ LSCF } & \multicolumn{3}{|c|}{ LSCF-CGO } \\
\hline Diffusivities & Value & Unit & $\begin{array}{c}\mathbf{E}_{\text {act }} \\
\left(\mathrm{kJ} \cdot \mathbf{m o l}^{-1}\right)\end{array}$ & Value & Unit & $\begin{array}{c}\mathbf{E}_{\text {act }} \\
\left(\mathrm{kJ} \cdot \mathrm{mol}^{-1}\right)\end{array}$ \\
\hline $\begin{array}{l}\text { Diffusion coefficient of the oxygen } \\
\text { ad-ions }\left(D_{\left.O^{-}-s_{L S C F}\right)}\right.\end{array}$ & $9 \times 10^{-8}$ & $\left(\mathrm{~m}^{2} \cdot \mathrm{s}^{-1}\right)$ & 184 & $4 \times 10^{-7}$ & $\left(\mathrm{~m}^{2} \cdot \mathrm{s}^{-1}\right)$ & 218 \\
\hline $\begin{array}{l}\text { Diffusion coefficient of the oxygen } \\
\text { ad-atoms }\left(D_{O-S_{L S C F}}\right)\end{array}$ & $3 \times 10^{-7}$ & $\left(\mathrm{~m}^{2} \cdot \mathrm{s}^{-1}\right)$ & 153 & $3 \times 10^{-7}$ & $\left(\mathrm{~m}^{2} \cdot \mathrm{s}^{-1}\right)$ & 153 \\
\hline $\begin{array}{l}\text { Diffusion coefficient of the oxygen } \\
\text { ad-molecules }\left(D_{O_{2}-s_{L S C F}}\right)\end{array}$ & $3 \times 10^{-7}$ & $\left(\mathrm{~m}^{2} \cdot \mathrm{s}^{-1}\right)$ & 153 & $3 \times 10^{-7}$ & $\left(\mathrm{~m}^{2} \cdot \mathrm{s}^{-1}\right)$ & 153 \\
\hline Kinetic constants & Value & Unit & $\begin{array}{c}\mathbf{E}_{\text {act }} \\
\left(\mathbf{k J} \cdot \mathbf{m o l}^{-1}\right)\end{array}$ & Value & Unit & $\begin{array}{c}\mathbf{E}_{\text {act }} \\
\left(\mathrm{kJ} \cdot \mathrm{mol}^{-1}\right) \\
\end{array}$ \\
\hline $\begin{array}{l}\text { Kinetic constant for excorporation } \\
k_{o x}^{L S C F / g a s}\end{array}$ & $1 \times 10^{-4}$ & $\left(\mathrm{~m}^{3} \cdot \mathrm{mol}^{-1} \cdot \mathrm{s}^{-1}\right)$ & 148 & $2 \times 10^{-5}$ & $\left(\mathrm{~m}^{3} \cdot \mathrm{mol}^{-1} \cdot \mathrm{s}^{-1}\right)$ & 149 \\
\hline $\begin{array}{l}\text { Kinetic constant for deionization } \\
k^{\text {deion }}\end{array}$ & $6.8 \times 10^{4}$ & $\left(\mathrm{~s}^{-1}\right)$ & 212 & $5.1 \times 10^{4}$ & $\left(\mathrm{~s}^{-1}\right)$ & 245 \\
\hline $\begin{array}{l}\text { Kinetic constant for desorption } \\
k^{\text {des }}\end{array}$ & $2.8 \times 10^{5}$ & $\left(\mathrm{~s}^{-1}\right)$ & 178 & $2.8 \times 10^{5}$ & $\left(\mathrm{~s}^{-1}\right)$ & 178 \\
\hline $\begin{array}{l}\text { Kinetic constant for oxidation at } \\
\text { TPBls } k_{o x}^{T P B l s}\end{array}$ & $2.3 \times 10^{-3}$ & $\left(\mathrm{~m} \cdot \mathrm{s}^{-1}\right)$ & 206 & $4.6 \times 10^{-5}$ & $\left(\mathrm{~s}^{-1}\right)$ & 286 \\
\hline $\begin{array}{l}\text { Kinetic constant for charge transfer } \\
\text { at LSCF/CGO } k_{+}\end{array}$ & $\begin{array}{c}\text { NOT } \\
\text { LIMITING }\end{array}$ & $\left(\mathrm{mol} \cdot \mathrm{m}^{-1} \cdot \mathrm{s}^{-1}\right)$ & - & $\begin{array}{c}\text { NOT } \\
\text { LIMITING } \\
\end{array}$ & $\left(\mathrm{mol} \cdot \mathrm{m}^{-2} \cdot \mathrm{s}^{-1}\right)$ & - \\
\hline $\begin{array}{c}\text { Kinetic constant for association } \\
k_{\text {ass }}\end{array}$ & $\begin{array}{c}\text { NOT } \\
\text { LIMITING }\end{array}$ & $\left(\mathrm{m}^{2} \cdot \mathrm{mol}^{-1} \cdot \mathrm{s}^{-1}\right)$ & - & $\begin{array}{c}\text { NOT } \\
\text { LIMITING }\end{array}$ & $\left(\mathrm{m}^{2} \cdot \mathrm{mol}^{-1} \cdot \mathrm{s}^{-1}\right)$ & - \\
\hline $\begin{array}{l}\text { LSCF surface coverage at } \\
\text { equilibrium for } P_{\mathrm{O}_{2}}=0.21 \mathrm{~atm}\end{array}$ & \multicolumn{3}{|c|}{ Value } & \multicolumn{3}{|c|}{ Unit } \\
\hline $\begin{array}{c}\text { Oxygen ions coverage at } \\
\text { equilibrium } \\
\theta_{O^{-}-s_{L S C F}}^{e q} \\
\end{array}$ & \multicolumn{3}{|c|}{$6 \times 10^{-3}$} & \multicolumn{3}{|c|}{$(-)$} \\
\hline $\begin{array}{c}\text { Oxygen atoms coverage at } \\
\text { equilibrium } \\
\theta_{O-s_{L S C F}}^{e q} \\
\end{array}$ & \multicolumn{3}{|c|}{$1 \times 10^{-3}$} & \multicolumn{3}{|c|}{$(-)$} \\
\hline $\begin{array}{c}\text { Oxygen molecules coverage at } \\
\text { equilibrium } \\
\theta_{O_{2}-s_{L S C F}}^{e q}\end{array}$ & \multicolumn{3}{|c|}{$1 \times 10^{-4}$} & \multicolumn{3}{|c|}{$(-)$} \\
\hline
\end{tabular}




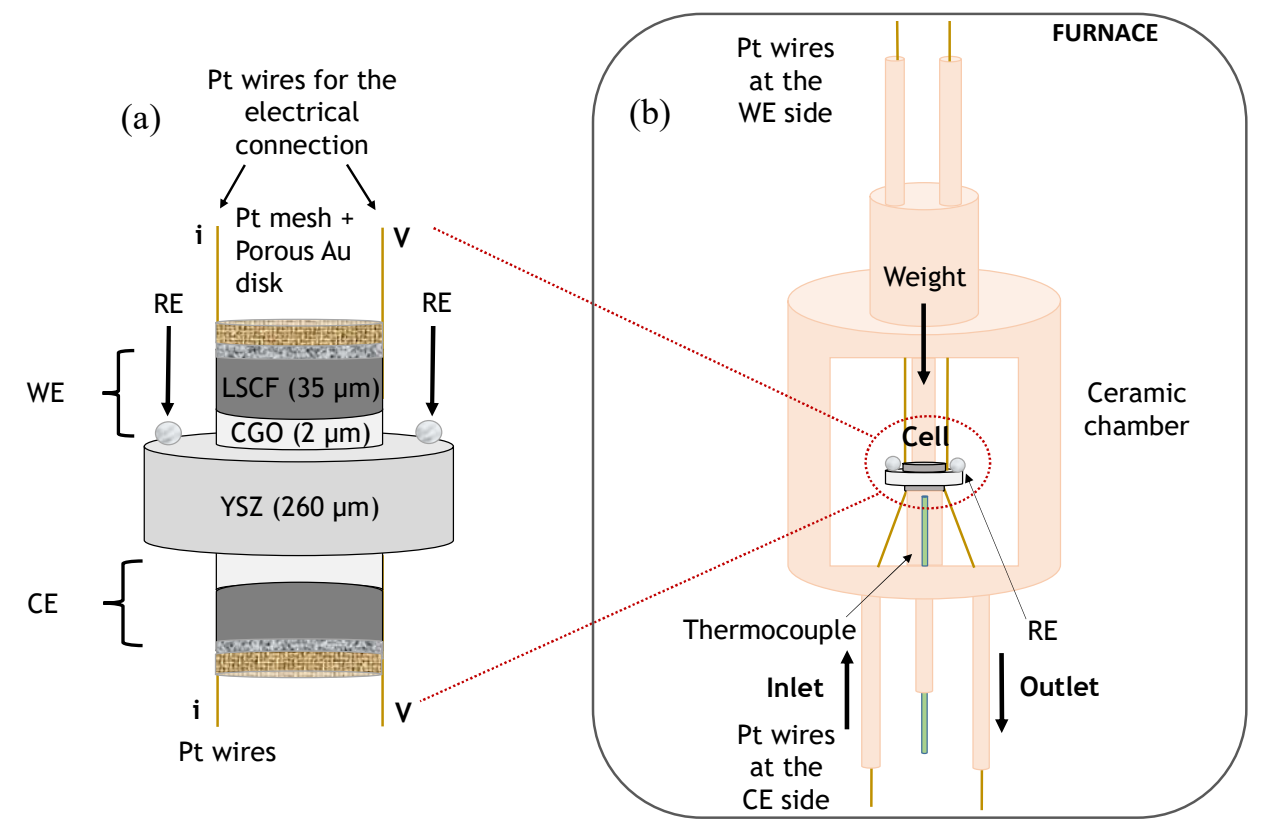

Fig. 1. (a) Schematic representation of the three-electrode cell and (b) description of the ceramic housing for tests in symmetrical configuration. 


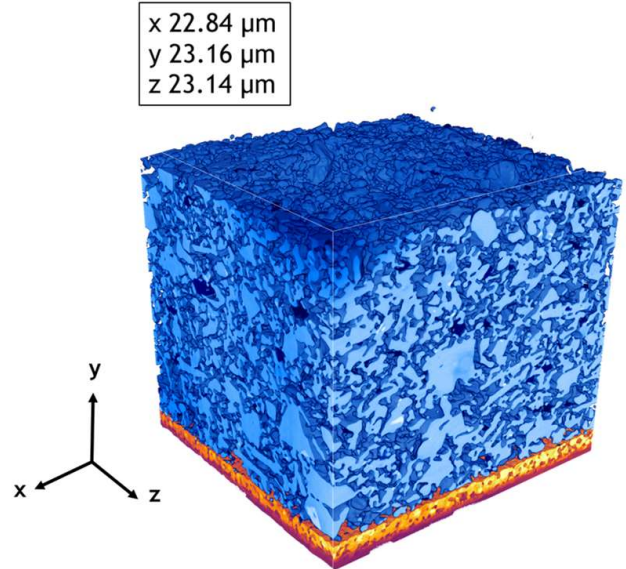

(a) LSCF

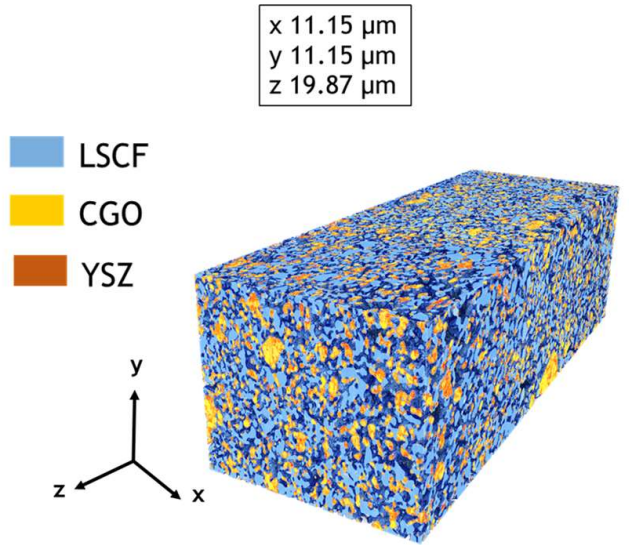

(b) LSCF-CGO

Fig. 2. (a) FIB-SEM reconstruction for the LSCF electrode. The tomography includes also the CGO barrier layer (in yellow) and few micrometers of the YSZ electrolyte (in brown).

(b) FIB-SEM reconstruction for the LSCF-CGO electrode [32]. 


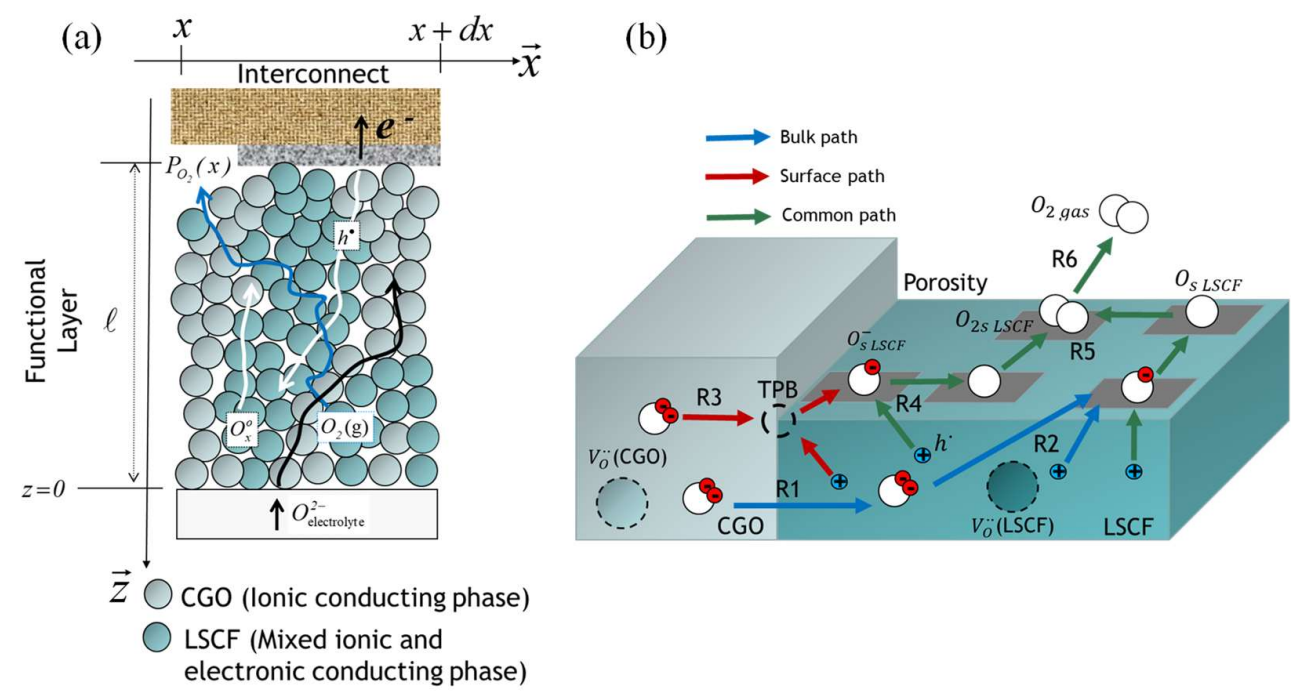

Fig. 3. (a) Electrode slice considered for the LSCF-CGO model with the system of coordinates. (b) Schematic description of the two reaction pathways implemented in the elementary kinetic model. The "bulk path" and the "surface path" are represented with blue and red arrows, respectively, the "common path" with green arrows. The reaction mechanism is represented in electrolysis mode. 

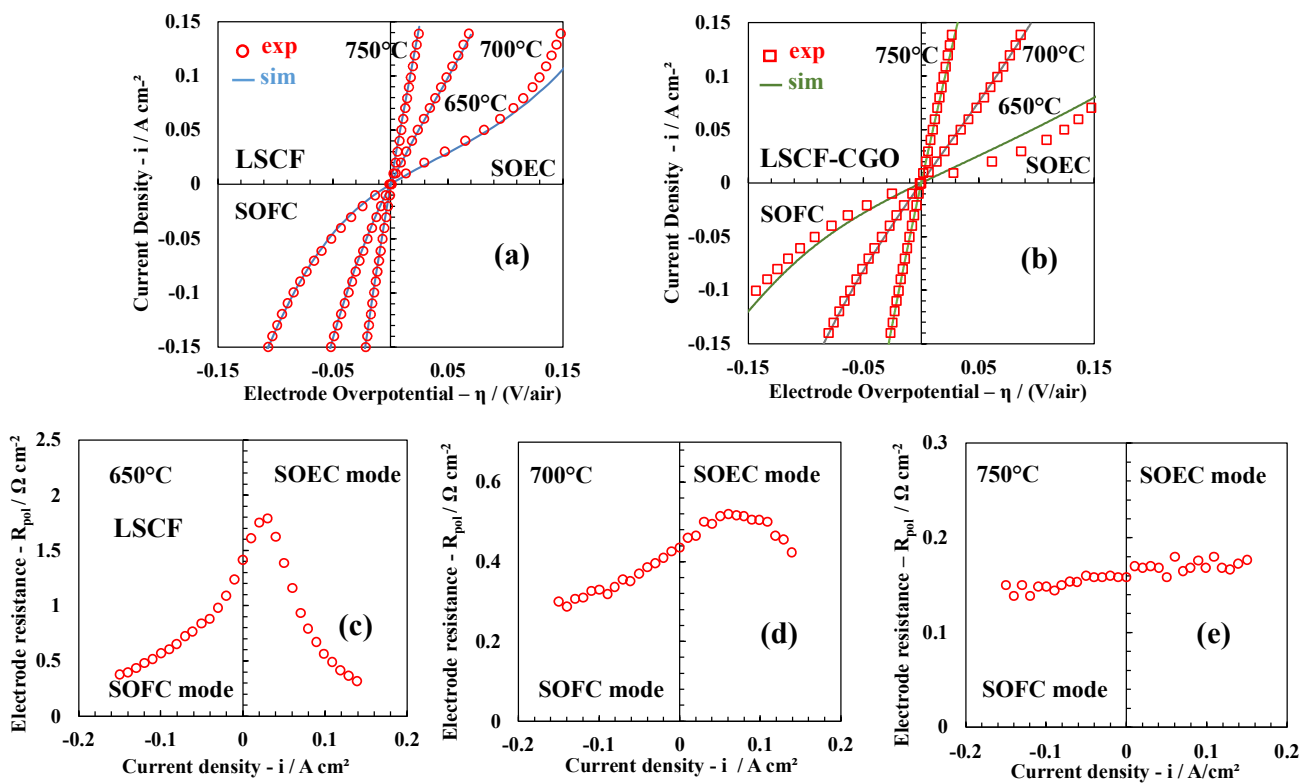

Fig. 4. Experimental and simulated experimental i- $\eta$ curves under air for (a) the LSCF and (b) the LSCF-CGO electrode [32], respectively. Experimental LSCF electrode polarization resistance plotted as a function of the current density at (c) $650^{\circ} \mathrm{C}$, (d) $700^{\circ} \mathrm{C}$ and (e) $750^{\circ} \mathrm{C}$. 

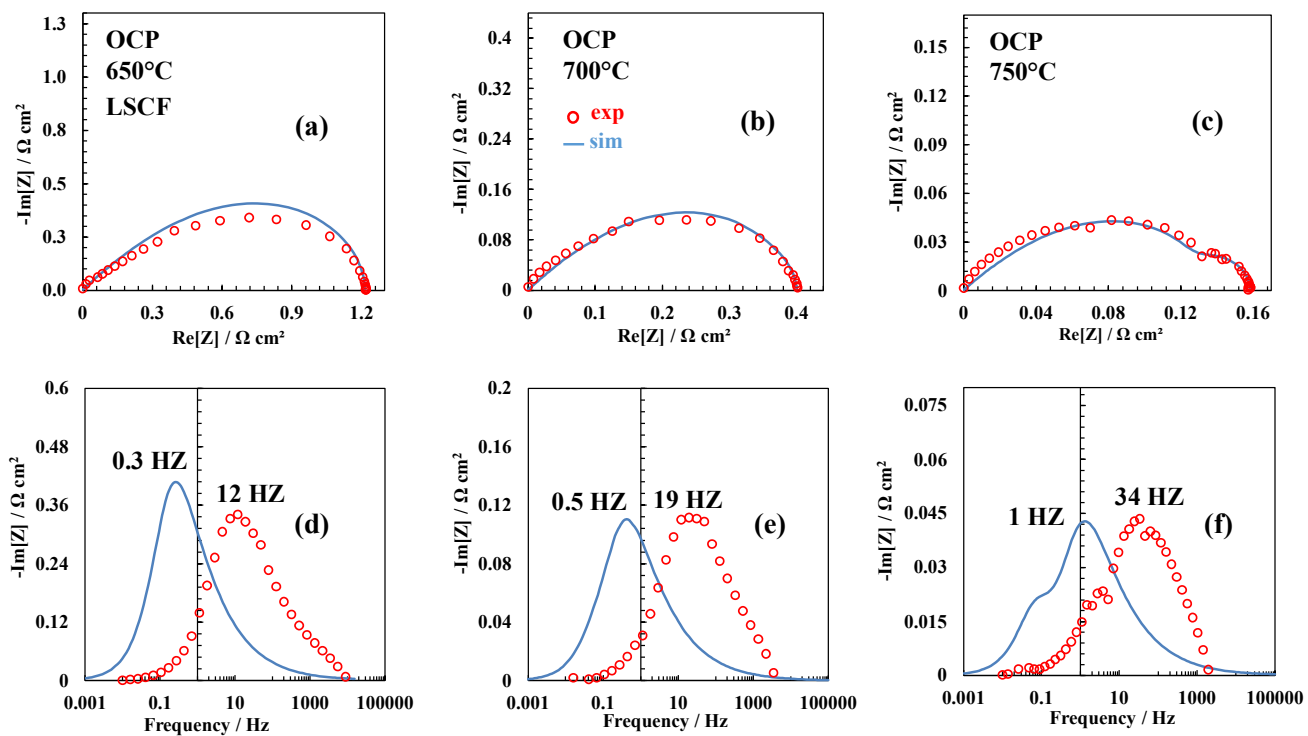

Fig. 5. Experimental and simulated impedance diagrams for the LSCF electrode at OCP.

Nyquist plots for (a) $650^{\circ} \mathrm{C}$, (b) $700^{\circ} \mathrm{C}$ and (c) $750^{\circ} \mathrm{C}$. Bode plots for (d) $650^{\circ} \mathrm{C}$, (e) $700^{\circ} \mathrm{C}$ and (f) $750^{\circ} \mathrm{C}$. 

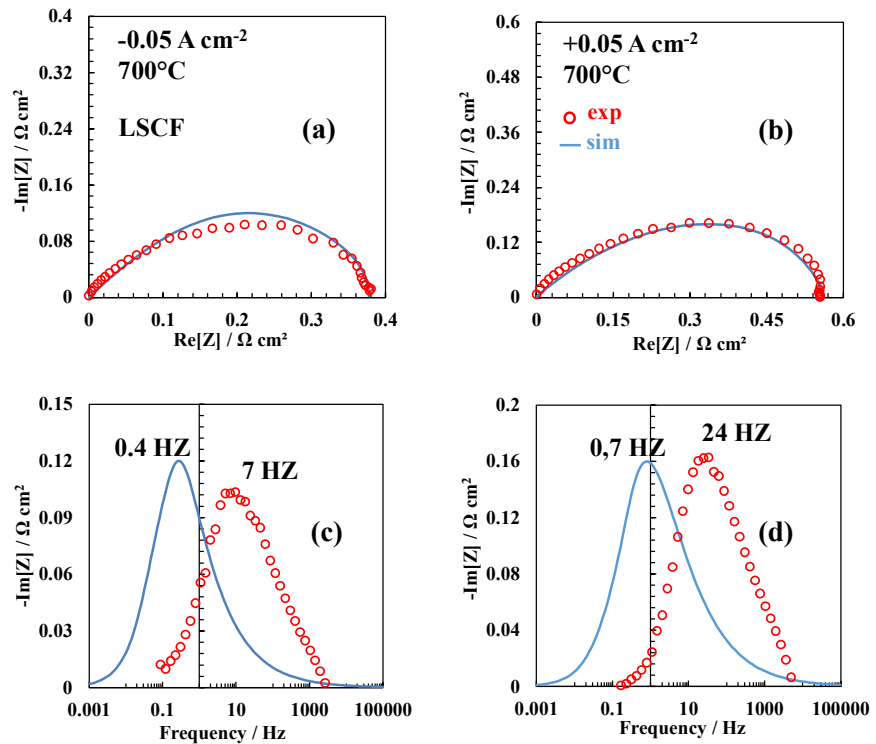

Fig. 6. Experimental and simulated impedance diagrams for the LSCF electrode at $700^{\circ} \mathrm{C}$ for $i_{d c}= \pm 50 \mathrm{~mA} \mathrm{~cm}^{-2}$. (a) and (b) Nyquist and (c) and (d) Bode plots. 

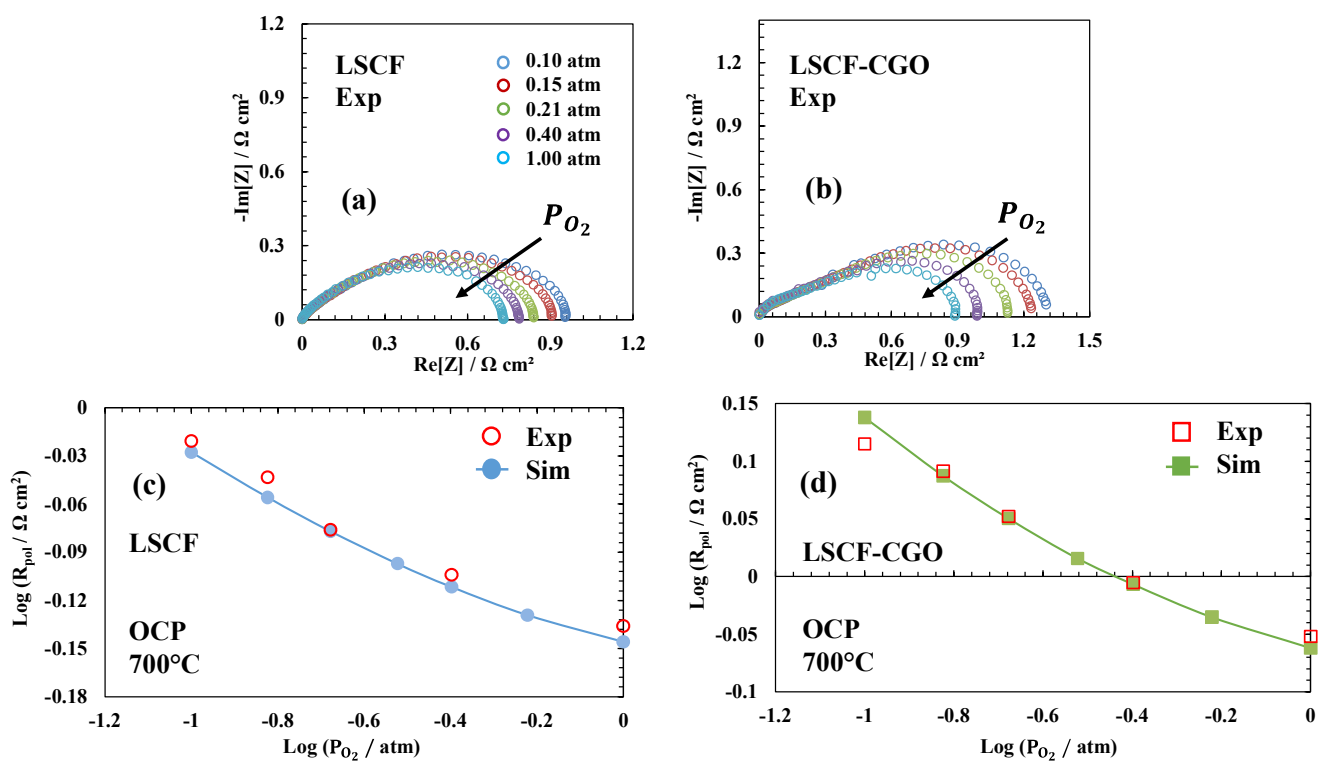

Fig. 7. Nyquist plots as a function of the oxygen partial pressure at $700^{\circ} \mathrm{C}$ for (a) the LSCF and (b) the LSCF-CGO electrode, respectively. Plot of the logarithm of the electrode polarization resistance as a function of the logarithm of the oxygen partial pressure for (c) the LSCF electrode and (d) the LSCF-CGO electrode. 

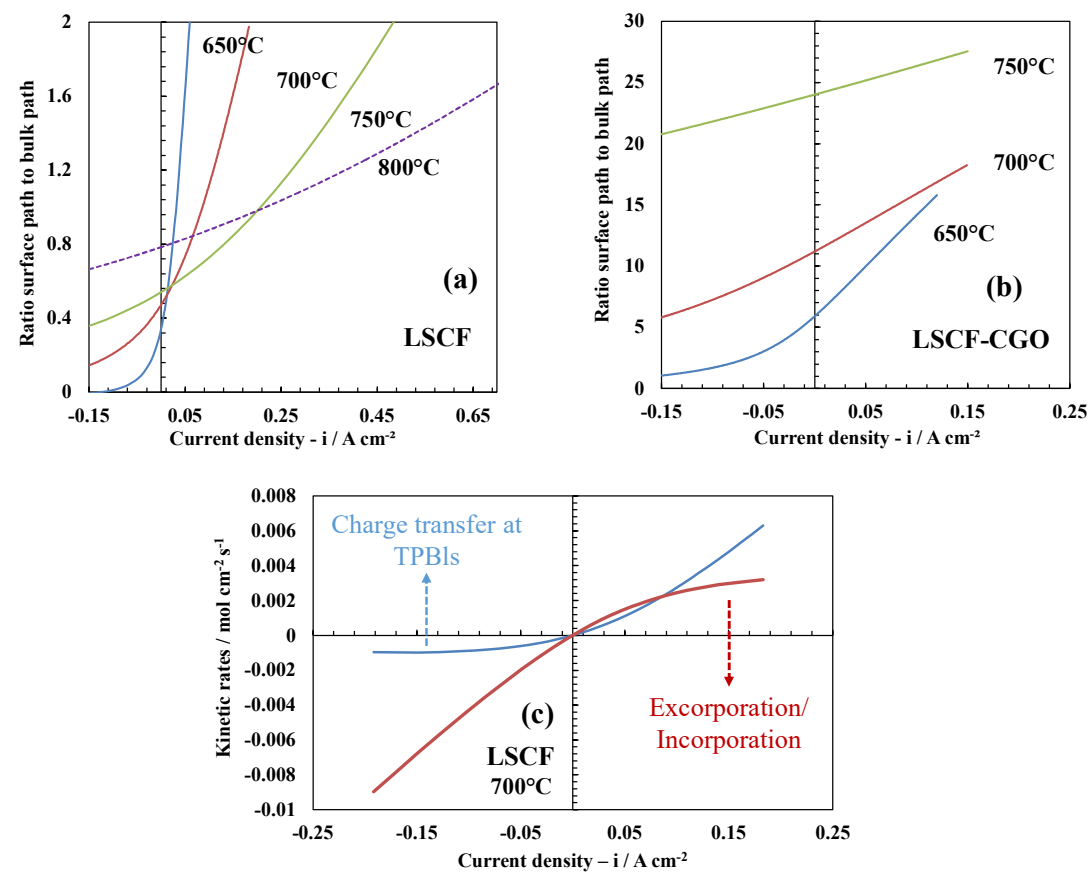

Fig. 8. Ratio of the surface to the bulk path under air for (a) the LSCF electrode and (b) the LSCF-CGO electrode. The kinetic rates for the charge transfer at TPBs and the oxygen incorporation/excorporation (integrated along the electrode thickness) are plotted versus the current density in (c) for the LSCF electrode at $700^{\circ} \mathrm{C}$. 

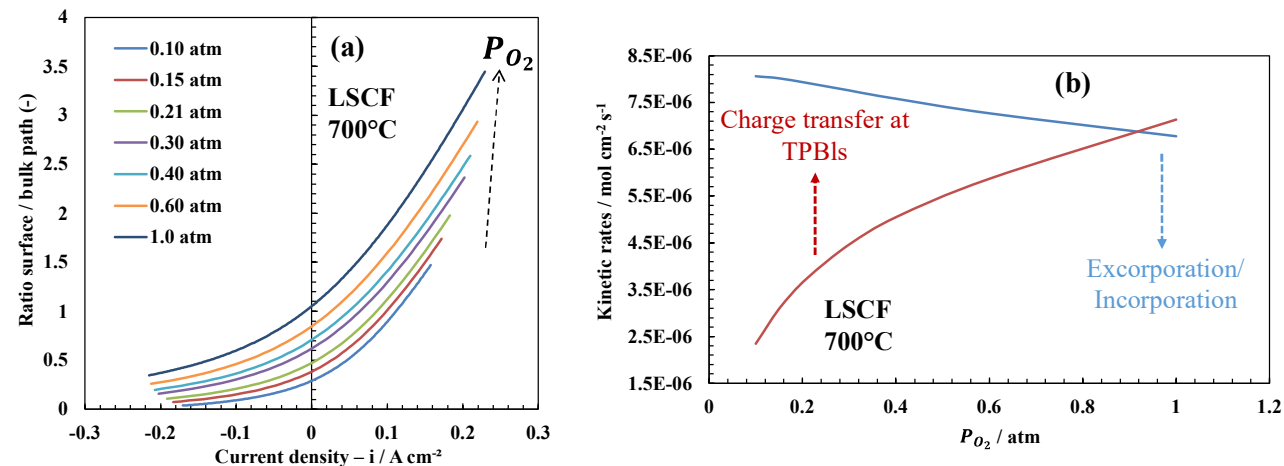

Fig. 9. (a) Ratio of the surface/bulk path as a function of the current density for each investigated oxygen partial pressure at $700^{\circ} \mathrm{C}$ for the LSCF electrode. (b) Kinetic rates of the oxygen excorporation/incorporation (blue) and the charge transfer at TPBls (red) as a function of the oxygen partial pressure computed close to the OCP (at $+0.225 \mathrm{~mA} \cdot \mathrm{m}^{-2}$ ) . 

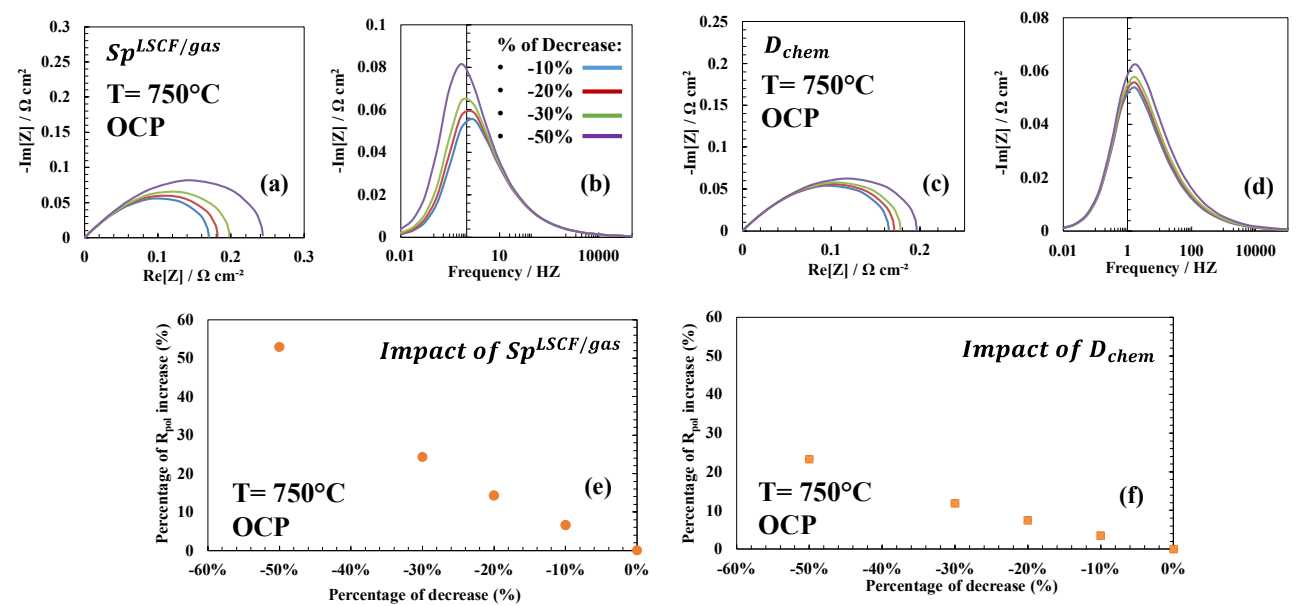

Fig. 10. Sensitivity analysis on the surface passivation and on the loss of ionic conductivity at $750^{\circ} \mathrm{C}$ under air at OCP. Nyquist and Bode plots evolution (a) and (b) for the surface passivation and (c) and (d) for the loss of ionic conductivity, respectively. Evolution of the polarization resistance with the decrease of (e) the specific surface area and of (f) the chemical diffusivity. 

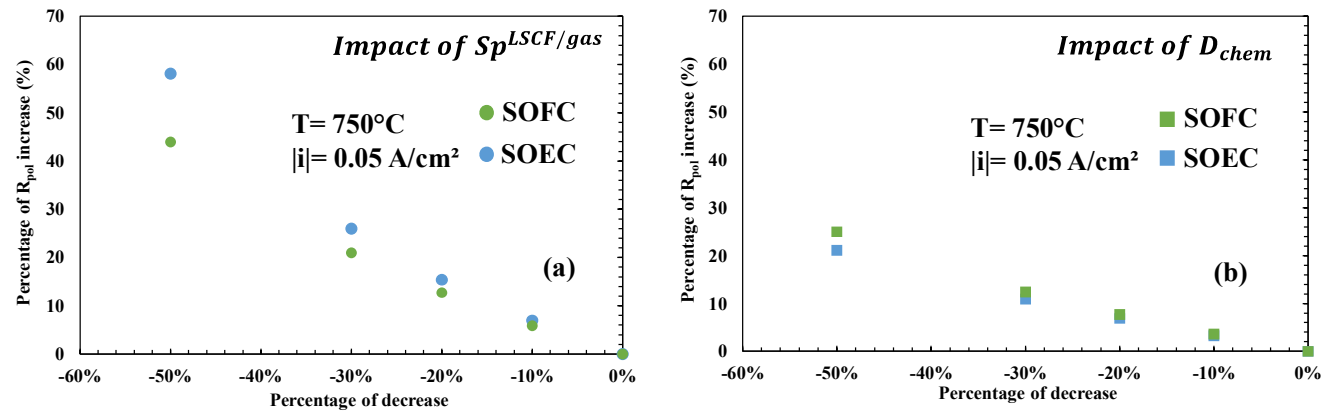

Fig. 11. Sensitivity analysis on (a) and (b) the surface passivation and the loss of ionic conductivity at $750^{\circ} \mathrm{C}$ under air with a dc current of $+/-50 \mathrm{~mA} \cdot \mathrm{cm}^{-2}$. The green points represent the values computed under cathodic polarization, while the blue points represent the values computed under anodic polarization. 


\section{SUPPLEMENTARY}

Information

Some of the results for the LSCF and LSCF-CGO electrodes are reported in the supplementary. The impedance diagrams for the WE and the CE versus the RE measured on the LSCF symmetrical cell are shown in Fig. S1. The superimposition of the two spectra confirms that the rules for the positioning of the RE are fulfilled. This result allows validating the reliability of the measurements.

In Fig. S2 and S3, it is shown that the LSCF-CGO model is able to predict accurately the shape of the impedance diagrams obtained in different conditions of temperature or polarizations. As for the LSCF electrode, a systematic frequency shift is observed between the simulations and the experiments. However, the increase of the characteristic frequency with the temperature and the polarization is well retrieved by the model.

In Fig. S4, the impedance diagrams as a function of the anodic polarization have been computed for the LSCF model at $700^{\circ} \mathrm{C}$ at $P_{O_{2}}=0.21 \mathrm{~atm}$. An improvement in performances have been found with the increasing of the dc current. In this condition, it can be noticed that a contribution due to the gas conversion in the electrode appears in the impedance spectra at low frequencies.

Finally, in Fig. S5, it is shown that the composite electrode is completely controlled by the surface path at $700^{\circ} \mathrm{C}$ (except at low oxygen partial under high cathodic polarization). Besides, as for the LSCF electrode, the contribution of the surface path is enhanced with increasing the oxygen partial pressure. 


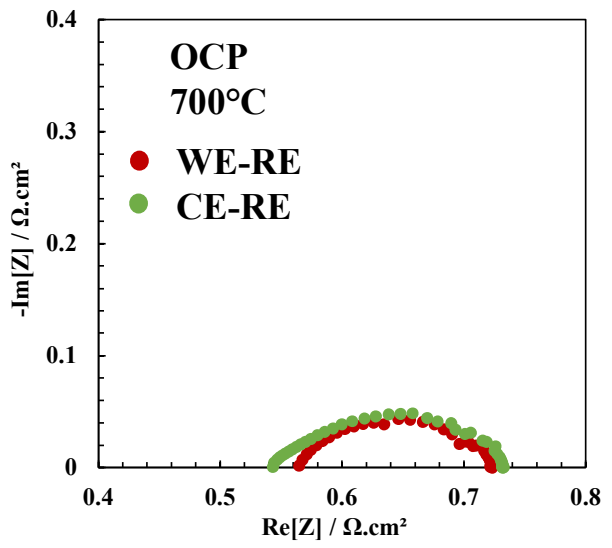

Fig. S1. Experimental impedance diagrams at $700^{\circ} \mathrm{C}$ at $\mathrm{OCP}$ for the WE-RE (red dots) and CE-RE (green dots), respectively, of the LSCF symmetrical cell. 

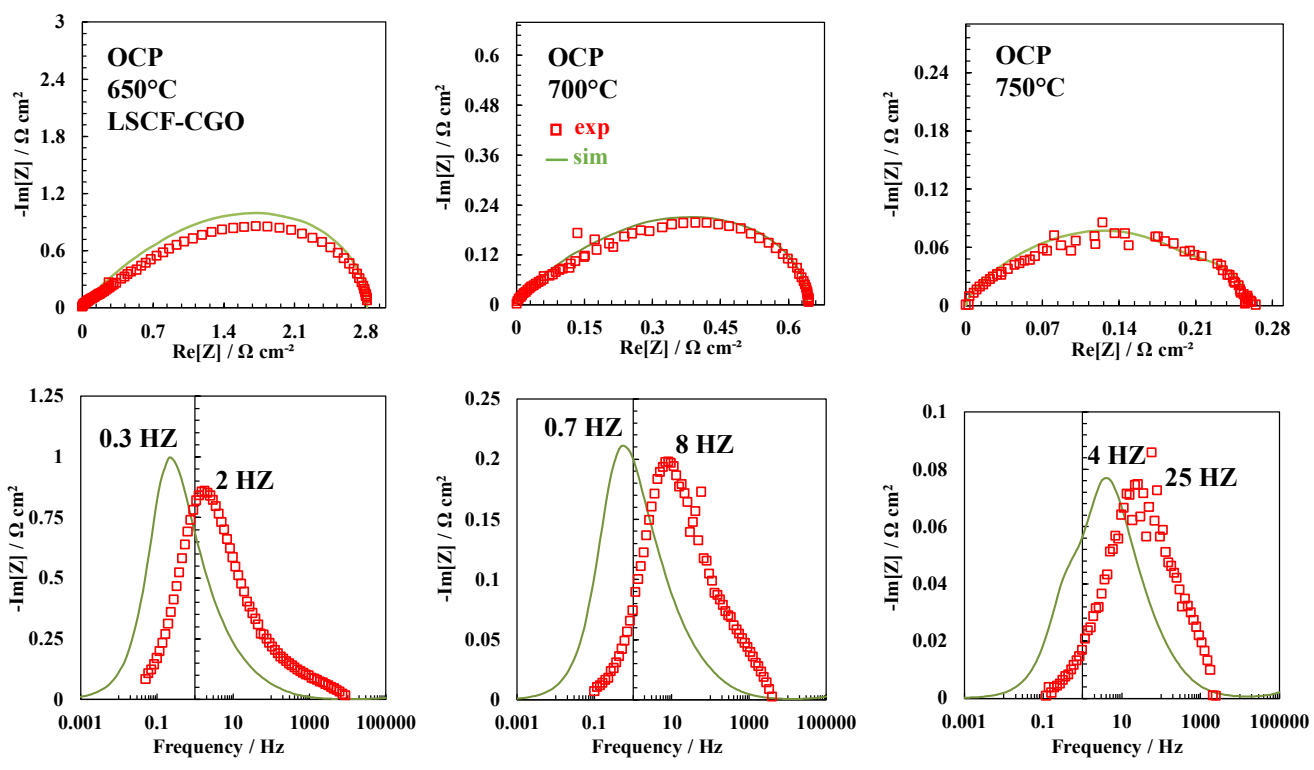

Fig. S2. Experimental and simulated impedance diagrams at OCP for the LSCF-CGO electrode. Nyquist plots for (a) $650^{\circ} \mathrm{C}$, (b) $700^{\circ} \mathrm{C}$ and (c) $750^{\circ} \mathrm{C}-$ Bode plots for (d) $650^{\circ} \mathrm{C}$, (e) $700^{\circ} \mathrm{C}$ and (f) $750^{\circ} \mathrm{C}$. 

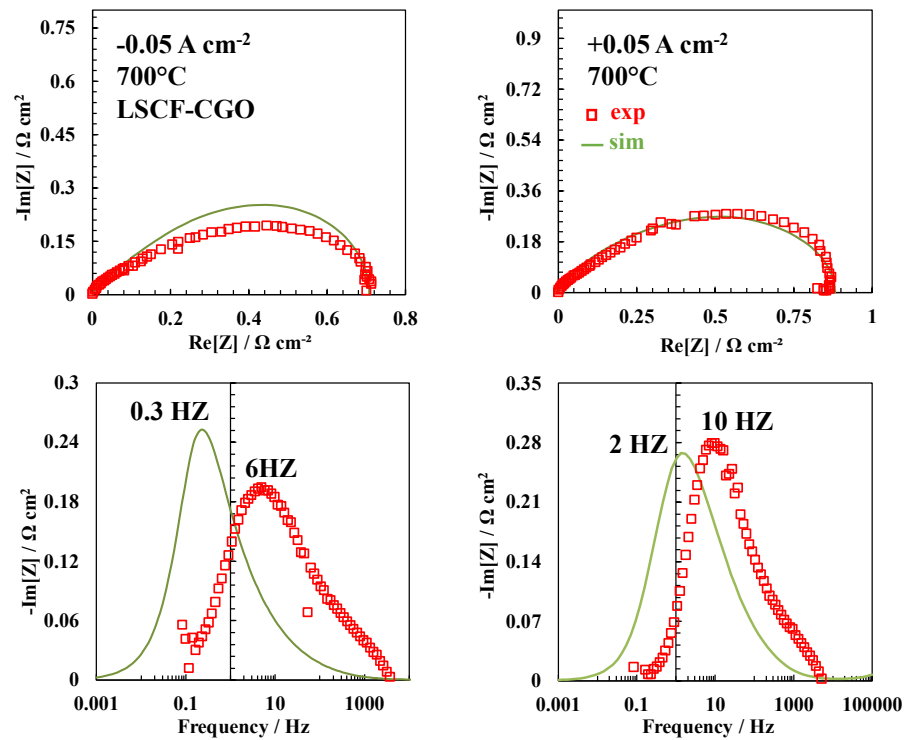

Fig. S3. Experimental and simulated impedance diagrams for the LSCF-CGO electrode at $700^{\circ} \mathrm{C}$ for $i_{d c}= \pm 50 \mathrm{~mA} \cdot \mathrm{cm}^{-2}$ (a) and (b) Nyquist and (c) and (d) Bode plots. 

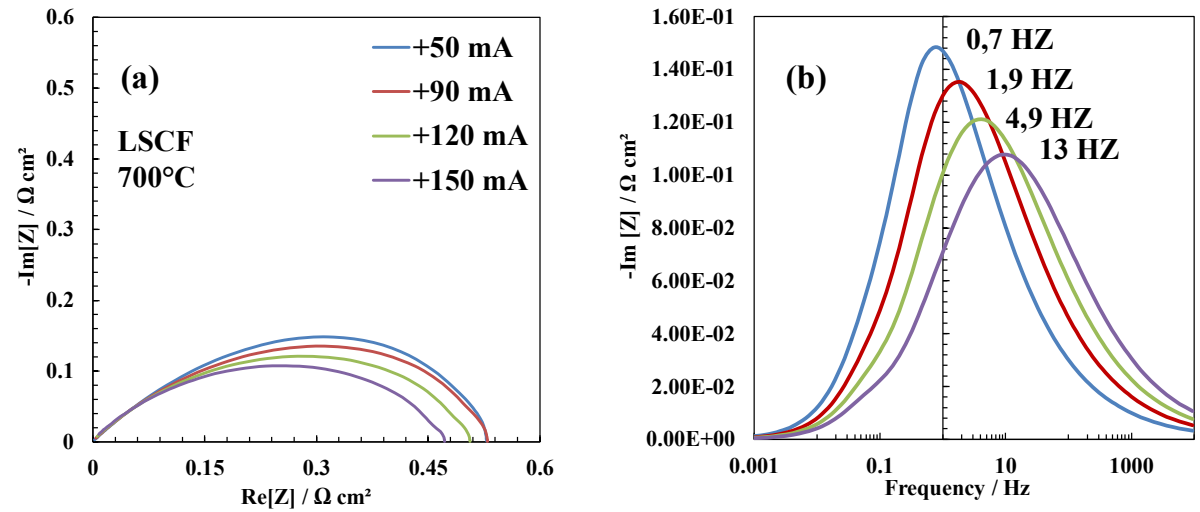

Fig. S4. Experimental and simulated impedance diagrams for the LSCF electrode at $700^{\circ} \mathrm{C}$ under air for $\mathrm{i}_{\mathrm{dc}}=+50,+90,+120$ and $+150 \mathrm{~mA} \cdot \mathrm{cm}^{-2}$ (a) and (b) Nyquist and Bode plots. 


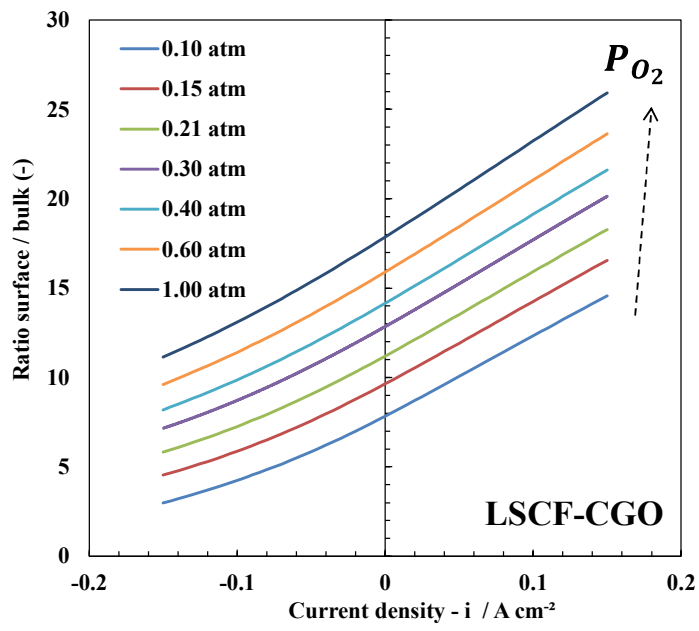

Fig. S5. Ratio of the surface/bulk path as a function of the current density for each investigated oxygen partial pressure at $700^{\circ} \mathrm{C}$ for the LSCF-CGO electrode. 